University of Louisville

ThinkIR: The University of Louisville's Institutional Repository

$5-2007$

\title{
The association of employment and out-of-pocket health care expenditures burden for poverty families.
}

William A. Carroll 1960-

University of Louisville

Follow this and additional works at: https://ir.library.louisville.edu/etd

\section{Recommended Citation}

Carroll, William A. 1960-, "The association of employment and out-of-pocket health care expenditures burden for poverty families." (2007). Electronic Theses and Dissertations. Paper 217.

https://doi.org/10.18297/etd/217

This Master's Thesis is brought to you for free and open access by ThinkIR: The University of Louisville's Institutional Repository. It has been accepted for inclusion in Electronic Theses and Dissertations by an authorized administrator of ThinkIR: The University of Louisville's Institutional Repository. This title appears here courtesy of the author, who has retained all other copyrights. For more information, please contact thinkir@louisville.edu. 
THE ASSOCIATION OF EMPLOYMENT AND OUT-OF-POCKET HEALTH CARE EXPENDITURES BURDEN FOR POVERTY FAMILIES

By

William A. Carroll

\author{
A Thesis \\ Submitted to the Faculty of the \\ Graduate School of the University of Louisville \\ In Partial Fulfillment of the Requirements \\ For the Degree of
}

\author{
Master of Arts \\ Department of Sociology \\ University of Louisville \\ Louisville, Kentucky
}

May, 2007 
THE ASSOCIATION OF EMPLOYMENT AND OUT-OF-POCKET HEALTH CARE EXPENDITURES BURDEN FOR POVERTY FAMILIES

By

William A. Carroll

A Thesis Approved on

March 27, 2007

By the following Thesis Committee:

Thesis Director 


\section{ACKNOWLEDGMENTS}

I would like to thank the sociology department at the University of Louisville, and especially Dr. Wayne Usui, for the support he and the department have given me in completing this thesis. I would also like to thank Dr. Melissa Andris and Dr. G. Edward Miller for their comments and assistance, which were invaluable in writing this thesis.

Thanks also to Dr. Steven Hill and Dr. Thomas Selden for their input. Finally, I would like to thank my employer, the Agency for Healthcare Research and Quality, and especially my supervisor, Dr. Doris Lefkowitz, for her unfailing support and encouragement. 


\title{
ABSTRACT \\ THE ASSOCIATION OF EMPLOYMENT AND OUT-OF-POCKET HEALTH CARE EXPENDITURES BURDEN FOR POVERTY FAMILIES
}

\author{
William A. Carroll
}

May 12, 2007

This thesis uses data from the 2002 Medical Expenditure Panel Survey in a quantitative examination of the capacity of the labor market in the United States to provide employment to the poor which enables them to afford health care. The out-ofpocket health care expenditures of the working poor are compared to those of the nonworking poor to see which group has the lower financial burden due to health care expenditures. Both bivariate and multivariate statistics are used, and show that employment lowers the financial burden of out-of-pocket health care expenditures for the poor. However, evidence is presented that shows this reduced burden may come at the cost of reduced health insurance coverage and reduced access to health care. 


\section{TABLE OF CONTENTS}

PAGE

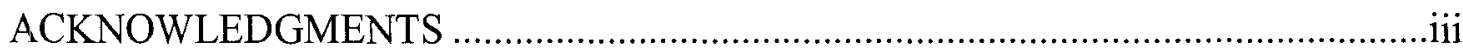

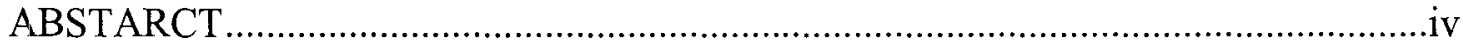

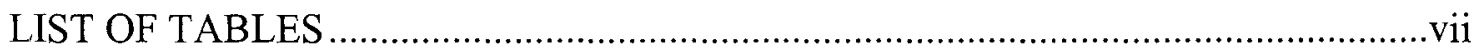

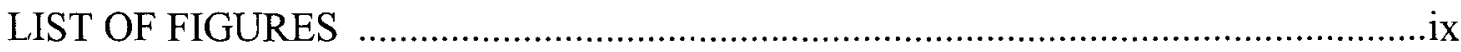

CHAPTER

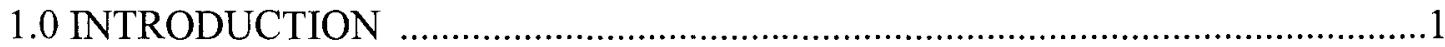

2.0 LITERATURE REVIEW ......................................................................

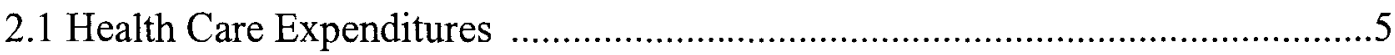

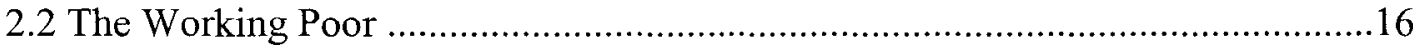

2.3 Welfare Reform ...............................................................................22

2.4 Literature Review Summary ......................................................... 31

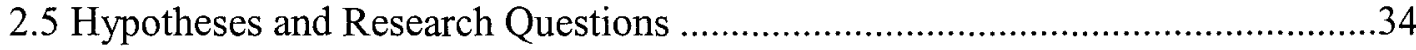

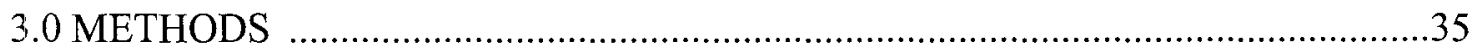

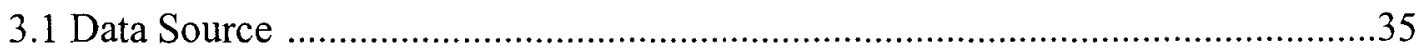

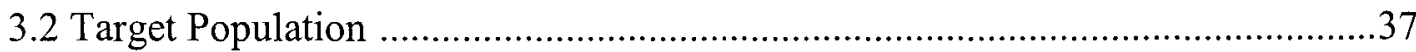

3.3 Dependent Variable: Health Care Expenditures Burden ..................................38

3.4 Multivariate Model ...........................................................................42

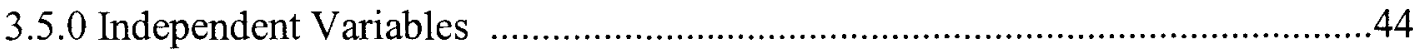

3.5.1 Employment Status ............................................................... 44

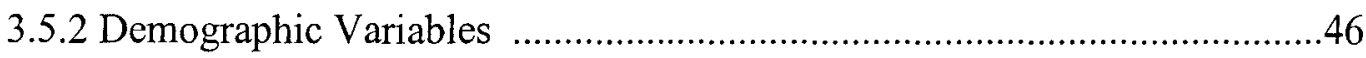




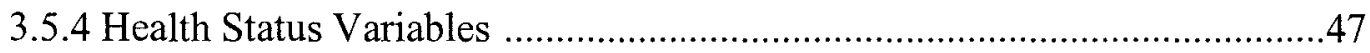

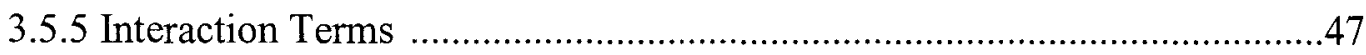

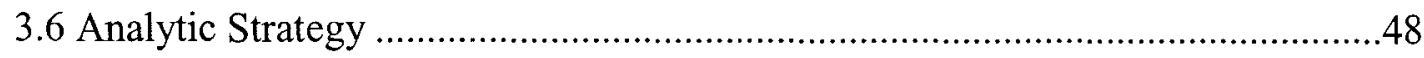

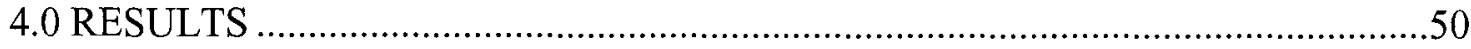

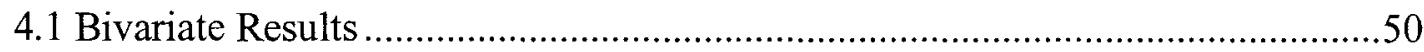

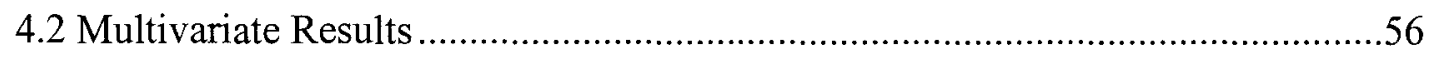

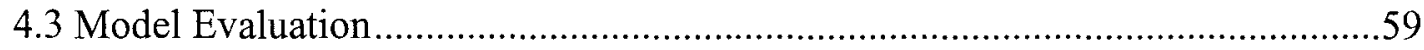

5.0 DISCUSSION

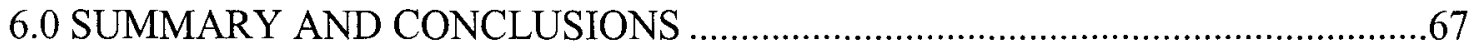

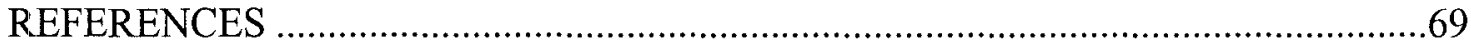

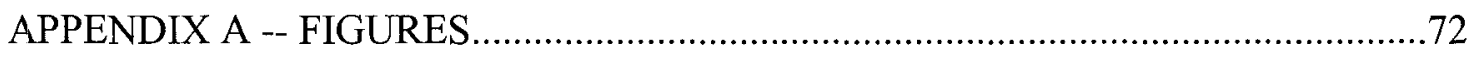

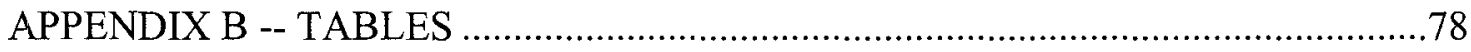

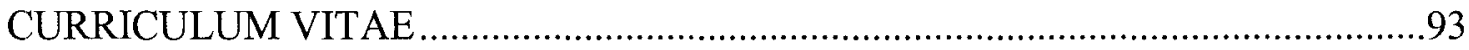




\section{LIST OF TABLES}

TABLE

PAGE

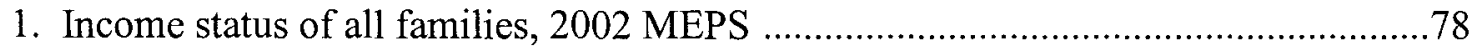

2. Cross-tabulation of high burden and very high burden for poverty families, 2002 MEPS .78

3. Demographic variables for poverty families, 2002 MEPS …………......................79

4. Access to care variables for poverty families, 2002 MEPS ........................................80

5. Health status variables for poverty families, 2002 MEPS .......................................81

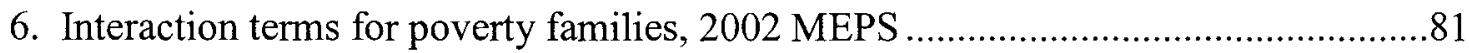

7. Distribution of the demographic variables across burden for poverty families, 2002 MEPS

8. Distribution of the access to care variables across burden for poverty families, 2002 MEPS

9. Distribution of the health status variables across burden for poverty families, 2002 MEPS

10. Distribution of the interaction terms across burden for poverty families, 2002 MEPS

11. Distribution of income and expenditures across employment measures for poverty families, 2002 MEPS

12. Distribution of employment measures across health insurance variables for poverty families, 2002 MEPS

13. Distribution of employment measures the across access to care variables for poverty families, 2002 MEPS

14. Logistic regression results using BLS-like employment measure, poverty families, 2002 MEPS 
15. Logistic regression results using months of employment, poverty

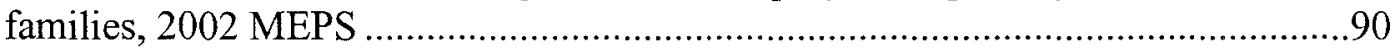

16. Comparing the association of employment and burden across the two burden measures for poverty families, 2002 MEPS 


\section{LIST OF FIGURES}

\section{FIGURE}

\section{PAGE}

1. Overlapping panel design of the 2002 MEPS

2. Family out-of-pocket health care expenditures for poverty families, 2002 MEPS

3. Family income for poverty families, 2002 MEPS 73

4. Health care expenditures as a percent of family income for poverty families, 2002 MEPS

5. Probability density curves for the percent of family income used to pay OOP health care expenditures, before and after natural log transformation for poverty families, 2002 MEPS

6. Employment status using a modified BLS definition for poverty families, 2002 MEPS

7. Probability density curve for the number of months worked for poverty families, 2002 MEPS

8. Categorized number of months worked for poverty families, 2002 MEPS 75

9. Scatter plot of months of work by percent of income spent on OOP health care, poverty families, 2002 MEPS .76

10..Percent burden by employment status for poverty families, 2002 MEPS .76

11. Percent burden by months worked for poverty families, 2002 MEPS .77 


\section{CHAPTER 1}

\section{INTRODUCTION}

The cost of health care in the United States has been rising dramatically in recent years. According to the National Center for Health Statistics (NCHS) the total health care expenditure in the United States for 2002 was $\$ 1.5$ trillion, an increase of 9.3 percent from the previous year (NCHS 2004). The United States spends a greater share of GDP (gross domestic product) on health care than any other industrialized country; 15 percent in 2002, compared to 11 percent for both Germany and Switzerland, and 10 percent for Canada, France, Iceland, Norway and Greece, the countries having the next largest shares (NCHS 2005). Yet the United States has lower life expectancies and higher infant mortality rates than all of those countries, which implies that health care resources are not being used effectively in the United States (World Health Organization 2006).

Out-of-pocket (OOP) health care expenditures, the amount that individuals pay themselves after any third party payer has paid the health care provider, increased 27.4 percent from 1996 to 2003, after adjusting for inflation (authors' calculation using data from the 1996 and 2003 Medical Expenditure Panel Survey). OOP health insurance premiums, a component of OOP health care expenditures (Short and Garner 2002), have been rising as well, increasing 52.7 percent for a family plan from 1996 to 2003 (authors' calculation using data from the 1996 and 2003 Medical Expenditure Panel Survey). OOP health care expenditures can create a serious financial burden for individuals and their 
families, and this burden has been increasing over time. For example, in 199615.8 percent of the population lived in a family that spent more than 10 percent of its disposable income on health care expenditures, and this increased to 19.2 percent of the population by 2003, a statistically significant increase (Banthin and Bernard 2006). In 2001, 27 percent of all personal bankruptcies were due to medical debt (Himmelstein et al. 2005).

While OOP health care expenditures can create a financial burden for families of all income levels, poverty families, the focus of this thesis, are most vulnerable. The causes of poverty have long been debated, and there is still no agreement as to the causes, but the explanations put forward have changed over time. Prior to the Great Depression of the 1930s, the popular explanation for poverty was that the poor were lazy and lacked the proper work ethic. However, with unemployment reaching a high of nearly 25 percent in 1933 (VanGiezen and Schwenk 2001), public perception of the poor began to change. The depression showed that economic forces beyond a person's control could push them into poverty. There emerged a consensus that the labor market was not capable of meeting the needs of all the people. This prompted the Roosevelt Administration to propose a "New Deal," a new social contract that would curb the excesses of private economic power, which were blamed for causing the depression, and create economic security for all citizens. The government created a social safety net that included Social Security for the elderly, Aid to Dependent Children (later expanded and renamed Aid to Families with Dependent Children) for poor single mothers, and Unemployment Insurance for the unemployed. This new social contract lifted many 
persons out of poverty and helped to mitigate the ill effects of labor market fluctuations (Patterson 2000).

The post World War II economic expansion lasted for almost 30 years and created unprecedented economic prosperity in the United States. However, this expansion faltered in the early 1970s, at which time business leaders, working with their allies in government, began in earnest to erode the New Deal social contract. Changes to the social safety net in the mid 1990s have pushed many poor families off of welfare and into the workforce, with the assumption that the labor market can adequately provide for anyone willing to work. The lessons of the Great Depression have been forgotten and the labor market is now viewed as the solution to poverty, and the poor are again seen as simply lacking the proper work ethic. This faith in the labor market seems unwarranted, considering that the minimum wage has not been raised since 1997, and most low wage jobs lack benefits such as health insurance and paid sick leave. In addition to the low quality of jobs available to the poor, many poor persons have deficits, such as a lack of higher education and minimal work experience, which further hinder their ability to be self-sufficient (Harrington 1962, Patterson 2000).

The capacity of the labor market to provide adequate employment for the poor is an issue of central importance for the formulation of social policy in the United States. This thesis provides evidence on one aspect of this issue by examining the relationship between employment and the ability to afford health care. In particular, this thesis will use data from the 2002 Medical Expenditure Panel Survey to compare the OOP health care expenditures of the working poor to that of the non-working poor to determine if employment leaves the working poor better able to afford health care. Both bivariate and 
multivariate analysis will be used, with logistic regression models used for the multivariate analysis. The methods section will provide complete details on the analysis plan. The five remaining chapters of this thesis include the literature review, methods, results, discussion, and summary and conclusions sections. 


\section{CHAPTER 2 \\ LITERATURE REVIEW}

The literature review is divided into three sections, followed by a summary section that discusses how the existing research impacts this thesis. The three main sections are: health care expenditures, the working poor, and welfare reform. The formal hypotheses are presented after the summary section.

\subsection{Health Care Expenditures}

There is no doubt that health care expenditures are rapidly increasing, but there is disagreement over the causes. As described by Berk and Monheit (2001), there are two dominant explanations: 1) the medical system is over-used by persons who are not really very sick, but have good insurance coverage and go to their doctor for trivial problems, and doctors that have an incentive to run every possible test, and 2) new medical breakthroughs allow expensive procedures for the very sick and the elderly that would not have been previously possible. Using data from the 1996 Medical Expenditure Panel Survey (MEPS), Berk and Monheit (2001) find that health care expenditures are concentrated in persons in very poor health, and that efforts to restrain expenditures should focus on this group. They suggest that more people would benefit from improved access to health care if expenditures were redistributed. When the population is ranked by health care expenditures the top one percent accounted for 27 percent of all expenditures in 1996, and the top five percent accounted for 55 percent. The bottom 50 
percent only accounted for 3 percent of all health care expenditures in 1996. The authors state that this distribution of expenditures has remained consistent for the previous 25 years.

Berk and Monheit (2001) acknowledge that expenditures should be skewed toward the seriously ill, but not to the near exclusion of half the population. In 1996 the average annual per person health care expenditure for persons in the bottom 50 percent was $\$ 122$, while the top one percent spent an average of $\$ 56,459$ per person. When looking at expenditures by insurance status, persons with private health insurance and in the bottom 50 percent of expenditures accounted for 5 percent of expenditures, while the uninsured in the bottom 50 percent only accounted for 1 percent of expenditures. The authors conclude that this data does not support the notion that the social safety net provides adequate care to all that need it.

Many researchers have examined the financial burden created by OOP health care expenditures (for example, Wyszewianski 1986, Hwang et al. 2001, Galbraith et al. 2005, and Shen and McFeeters 2006). OOP health care expenditures are usually examined at the family level since the financial resources of the family are typically used to pay for the health care of any family member. For example, children generate health care expenditures but have no income, and an unemployed spouse can generally depend on his or her spouse to help pay for their health care. The relative financial burden created by OOP health care expenditures is measured as the ratio of expenditures and income. Therefore, it is total family OOP health care expenditure and total family income that are the main determinants of financial burden. 
According to Wyszewianski (1986), national catastrophic health insurance, to protect families from high health care expenditures, has long been debated, but never enacted. However, these proposed plans focus on high cost medical care, such as cancer treatment or the care resulting from a traumatic accident, and may be missing the majority of individuals and families that have a high financial burden resulting from OOP health care expenditures.

Wyszewianski (1986) uses data from the 1977 National Medical Care Expenditure Survey (NMCES) to examine the characteristics of families with a financial burden caused by OOP health care expenditures and finds that the majority with a high burden have modest expenditures. Three overlapping groups are used; families with expenditures exceeding 5, 10 and 20 percent of family income, respectively. Wyszewianski (1986) does not indicate whether health insurance premiums are included or excluded from expenditures. Independent variables include income measured as a percent of the poverty level, age of the head of household, and employment status of the head of household, measured as employed all year, employed part year, and unemployed all year.

Wyszewianski (1986) finds that about 20 percent of all families had expenditures exceeding 5 percent, and 4.2 percent of families had expenditures that exceed 20 percent of family income. Although only 9.6 percent of all families had OOP health care expenditures exceeding 10 percent of family income, these families total expenditures represented slightly more than a quarter $(25.3 \%)$ of all OOP health care expenditures. $\mathrm{He}$ finds that the families with the highest burdens tend to be low income families. Among families that exceeded 20 percent burden, about 66 percent were below the official 
poverty level. A large percentage of families with a high burden had relatively small expenditures; among families that spent 20 percent or more of their family income for OOP health care expenditures, 26.5 percent spent no more than $\$ 500$ and 46.4 percent spent no more than $\$ 1000$. Families whose head of household was 65 years old or older also had unusually high burdens, with 31.8 percent of all such families exceeding 20 percent burden. Wyszewianski (1986) finds that among all families exceeding 20 percent burden, 50.6 percent had an unemployed head, and 45.1 percent had an employed head at least part of the year (employment status was unknown in $4.3 \%$ ).

Galbraith et al. (2005) examined the financial burden of OOP health care expenditures for families with children, using data from the 2001 Medical Expenditure Panel Survey (MEPS). There were 4,531 families with children in the 2001 MEPS. Galbraith et al. (2005) find socioeconomic disparities, as well as disparities by insurance type. They use three measures of financial burden; the amount of OOP expenditures per $\$ 1000$ of income, a dichotomous variable to identify families that spent 10 percent or more of family income on OOP health care, and a natural log transformation of the ratio of OOP expenditures to income. OOP health insurance premiums are included as health care expenditures. For their multivariate model they follow the behavioral model of health care first developed by Aday and Anderson in the 1960s (Aday and Anderson 1975). This model specifies three main groups of independent variables; predisposing variables, enabling variables and need variables. Predisposing variables are the race or ethnicity of the family reference person, family size, highest level of education in the family, geographic region and rural/urban residence. Enabling variables are family income, defined as categories based on the official poverty level, and health insurance 
status. Need variables are two family level health measures which indicate if anyone in the family reported their health as fair or poor, and whether anyone in the family had a health problem that limited their daily activities.

Galbraith et al. (2005) find that overall families spent about $\$ 60$ per $\$ 1000$ of family income on OOP health care expenses. Poverty families had the highest burden, spending on average $\$ 119.66$ per $\$ 1000$ of income, and burden steadily decreased with increasing income to where high income families only spent $\$ 37.75$ per $\$ 1000$ of income. Using their dichotomous burden measure they find the same relationship, with 28.3 percent of poverty families spending 10 percent or more of family income for OOP health care expenditures, compared to 6.3 percent of high income families.

Sub-setting to low income families (below $200 \%$ of poverty), they find that families uninsured all year were not different from families covered by public insurance, but that families covered by private insurance had a financial burden that was more than seven times greater than both uninsured families and families with public insurance. When health insurance premiums are excluded this difference is reduced but not eliminated. Although families with public insurance had a financial burden similar to uninsured families, they were significantly different regarding access to care. For example, publicly insured families averaged 3.6 doctor visits per family member, compared to 0.6 visits for uninsured families. Unfortunately, the paper does not mention the effect, if any, of the other independent variables in the model.

Hwang et al. (2001), using data from the 1996 MEPS, examined the relationship between OOP health care expenditures and chronic health conditions for individuals. They also examine the characteristics of families with high levels of spending for health 
care. The dependent variable is mean OOP health care expenditures. OOP health insurance premiums were not included as health care expenditures. Independent variables are the number of chronic health conditions, age, sex, race and ethnicity, insurance status and poverty status. Descriptive and multivariate analysis is used.

At the person level Hwang et al. (2001) find that the mean OOP expenditure increases for each additional chronic condition, but at a decreasing rate. Persons without a chronic condition had a mean OOP expenditure of $\$ 249$ compared to $\$ 433$ for persons with one chronic condition, $\$ 733$ for persons with two chronic conditions and $\$ 1,134$ for persons with three or more chronic conditions. The linear regression models, one for persons under age 65 and one for persons 65 and older, showed that the mean OOP expenditure increased with the number of chronic conditions, as well as with age and income, and varied by health insurance status. Persons under age 65 and covered by Medicaid had the lowest mean OOP expenditure, compared to persons with private insurance or uninsured. Uninsured persons had the highest mean OOP expenditure but, in a separate analysis, had less access to care than insured persons.

Sub-setting to persons without a chronic condition, about 45 percent of the uninsured had no medical care at all during the year, compared to just 16 percent with private insurance. At the family level they find that families headed by someone 65 years old or older had the highest mean expenditure. Families that have a person with a chronic condition were more than two and a half times as likely as families lacking such a person to spend at least $\$ 1,000$ OOP yearly. Overall families spent 5.1 percent of family income for OOP health care expenditures, and 9 percent of all families spent more than 10 percent of family income for OOP expenditures. 
Using data from the 2002 National Survey of America's Families (NSAF), Shen and McFeeters (2006) examined the OOP health care expenditures of adults 18 to 64 with health insurance, and their families, to see if the different types of insurance differed in their ability to protect against high OOP expenditures. OOP health care expenditures are measured with a single question asking the respondent the total amount spent on health care during the year. The insurance types were employer sponsored private, private nongroup, and public. They also examine OOP expenditures, and expenditure burden, by income level, defining low income as below 200 percent of the official poverty level, and high income as 200 percent or greater.

The NSAF is a nationally representative survey, conducted by the Urban Institute, using a dual-frame methodology consisting of Random Digit Dialing (RDD) telephone interviews and an area sample using in-person interviews. The 2002 survey collected data on more than 43,000 non-elderly adults, and had a response rate of 52 percent. OOP expenditures, excluding insurance premiums, are categorized as less than $\$ 500, \$ 500$ to $\$ 2,000$, and over $\$ 2,000$, labeled as low, moderate and high. Expenditure burden is categorized as $0-1 / 2$ percent of family income, $1 / 2-5$ percent of family income, and greater than 5 percent of family income, labeled as low, moderate and high. Shen and McFeeters (2006) justify this seemingly low threshold for high burden by noting that the federal government, in designing the State Children's Health Insurance Program, considers an OOP health care expenditure of 5 percent or more to be a hardship for the family. They use both descriptive analysis and multinomial logit modeling to study the differences in expenditures and expenditure burden between low and high income populations, and insurance type. Independent variables include insurance type, family health need 
measures and demographic measures, including adult work status, coded as not employed, part-time, or full-time.

Shen and McFeeters (2006) do not find a big difference in the percent of families with a health care expenditure exceeding $\$ 2,000 ; 13$ percent for low income families compared to 16 percent for high income families. However, there are large differences regarding families with a high expenditure burden, where 28 percent of low income families had a high burden, compared to only 7 percent of high income families. Looking at high expenditure burden by insurance type they find large disparities between low and high income families with respect to employer sponsored and private non-group insurance, but not with public insurance. Among families with employer sponsored health insurance low income families were nearly 5 times more likely to have a high burden than were high income families, and among families with private non-group insurance low income families were 3 times more likely to have a high burden. Overall, among those families with a high burden 14 percent had public insurance, with no significant difference between income categories. The results of the multinomial logit model confirmed that public health insurance provided better protection from a high financial burden than employer sponsored insurance; low income families with public insurance were only 0.19 times as likely to have a high burden as compared to low income families with employer sponsored insurance. For both low and high income groups, having private non-group insurance increased the odds of having a high burden, as compared to employer sponsored insurance. Also for both income groups, having an adult or child in poor health, or having an adult 65 years old or older, increased the odds of having a high burden. 


\section{Summary}

The literature presented in this section is diverse and examines health care expenditures from different perspectives. Shen and McFeeters (2006) use data from the NSAF, while the others use data from the MEPS, or its predecessor, the NMCES. The MEPS and NMCES provide very good measures of health care expenditures, since that is the primary focus of both surveys. However, the health care expenditure measure in the NSAF is much less rigorous, using only a single question to capture the health care expenditures of the entire family for the entire year. Shen and McFeeters (2006) address this issue and state that the expenditure measure from the NSAF compares favorably to the MEPS measure; however, this is potentially a limitation of the Shen and McFeeters (2006) study.

Berk and Monheit (2001) examine the overall distribution of expenditures and find that expenditures are skewed toward persons in very poor health. This is supported by Hwang et al. (2001), who find that families with a member having a chronic health condition are more likely to have a high financial burden, and Shen and McFeeters (2006), who find that families with a member in poor health are also more likely to have a high financial burden.

OOP health insurance premiums are not included as OOP health care expenditures in all of the research examining the family level financial burden created by OOP health care expenditures. Galbraith et al. (2005) include insurance premiums as health care expenditures while Hwang et al. (2001) and Shen and McFeeters (2006) do not include premiums. Wyszewianski (1986) does not state whether premiums were 
included or excluded. Of course, the ability to include premiums depends on the availability of premium data, which is not widely available.

This research also uses different methods of measuring financial burden, with the categorized ratio of expenditures to income being the most common. Wyszewianski (1986), Galbraith et al. (2005), and Shen and McFeeters (2006) use the ratio of expenditures to income, but categorize it differently. Both Wyszewianski (1986) and Shen and McFeeters (2006) create three dichotomous measures from the ratio of expenditures to burden. However, Wyszewianski (1986) creates overlapping categories while Shen and McFeeters (2006) create mutually exclusive categories. Also, the choice of cut points on the distribution differs, with Wyszewianski (1986) choosing 5, 10 and 20 percent, and Shen and McFeeters (2006) using 0-1/2 percent, $1 / 2-5$ percent and greater than 5 percent. Galbraith et al. (2005) use only 10 percent or more burden, as well as a natural $\log$ transformation of the ratio. Other measures used include the amount spent per $\$ 1,000$ income (Galbraith et al. (2005)), the mean expenditure (Hwang et al. 2001), and the absolute OOP expenditure categorized as less than $\$ 500, \$ 500$ to $\$ 2000$ and more than $\$ 2000$ (Shen and McFeeters (2006)).

Wyszewianski (1986), Galbraith et al. (2005), and Shen and McFeeters (2006), find that poverty families have a higher financial burden from OOP health care expenditures than families of higher income. Wyszewianski (1986) finds that among families with a 20 percent or greater burden, 66 percent are poverty families; Galbraith et al. (2005) find that 28.3 percent of poverty families have a 10 percent or greater burden compared to 6.3 percent of high income families; Shen and McFeeters (2006) find that among insured families 28 percent of low income families have a 5 percent or greater 
burden compared to 7 percent of high income families. Although these measures are not directly comparable, they all tell a similar story about the relationship between poverty and health care burdens.

Two of the studies, Wyszewianski (1986) and Shen and McFeeters (2006), use employment status as an independent variable. Wyszewianski (1986) uses the employment status of the head of household, while Shen and McFeeters (2006) use the employment status of a randomly selected adult in the family. Both of these methods potentially result in significant measurement error, since they may exclude adults in the family with substantial employment. Wyszewianski (1986) measures employment as employed all year, employed part year, and unemployed all year; Shen and McFeeters (2006) measure employment as employed full-time, employed part-time, and unemployed. Wyszewianski (1986) is able to use an employment measure that characterizes employment for a full year, since the NMCES captures those data, whereas Shen and McFeeters (2006) are limited to a single point-in-time employment measure from the NSAF. Wyszewianski (1986) finds that families with an unemployed head of household are somewhat more likely to have a burden exceeding 20 percent. Shen and McFeeters (2006) do not discuss the effect of employment on burden.

Three of the studies, Galbraith et al. (2005), Hwang et al. (2001), and Shen and McFeeters (2006) include health insurance in their analysis of family health care expenditure burden, and all find that public health insurance offers the best protection from a high expenditure burden. Galbraith et al. (2005) find that uninsured low-income families have a burden similar to publicly insured low-income families, but Hwang et al. (2001) find that among all families, uninsured families had the highest mean expenditure. 
Shen and McFeeters (2006) exclude the uninsured, but is the only study to examine the difference between private group (i.e., employer sponsored) and private non-group health insurance and find that private non-group insurance is associated with increased burden.

The studies that include age as an independent variable, Wyszewianski (1986), Hwang et al. (2001), and Shen and McFeeters (2006), find that families with a member 65 years old or older have a higher health care expenditure burden.

\subsection{The Working Poor}

The working poor, as defined by the Bureau of Labor Statistics (BLS), are those persons that worked 27 weeks or more during the year, but whose income was not above the official poverty level. The BLS estimates that 7.4 million workers, 5.3 percent of all working persons, were classified as poor in 2002, a nearly half percent increase from 2001, but lower than the all-time high of 6.7 percent in 1993 (BLS Report 976 2004). Full-time workers are less likely to be poor, as compared to part-time workers ( $3.8 \%$ versus $10.9 \%$ respectively), however, about $2 / 3$ of the working poor worked full-time.

Overall, the working poor are mostly white (about $71 \%$ ). However, within racial groups, white and Asian workers had nearly identical rates of poverty ( $4.5 \%$ and $4.6 \%$ respectively), as did black and Hispanic workers (10.5\% and $10.4 \%$ respectively).

Overall, 6.0 percent of working women were poor, compared to 4.7 percent of men. However, when broken-down by race, the greatest difference between working men and women is among blacks, with 13.1 percent of working black women being poor compared to 7.4 percent of black men. The BLS attributes this in part to the fact that black women are much more likely than women of other races to be single parents. Young workers were more likely to be poor than were older workers, with 10.2 percent 
of 20 to 24 year old workers being poor, and this rate steadily declined across age categories to 2.4 percent of working persons 65 years old or older being poor. The report also finds that educational attainment is related to being working poor, with only 1.6 percent of workers with a college degree being poor, compared to 6.1 percent of workers with only a high school diploma, and 14.6 percent of workers lacking a high school diploma.

At the family level the BLS defines a family as working poor if at least one person in the family was working, or looking for work, for at least 27 weeks during the year and the total family income is below the official poverty level. In 2002 the BLS estimates that 4.0 million working families, 6.3 percent of all working families, were poor. Married couple families were much less likely to be working poor than were families headed by single women $(8.1 \%$ versus $21.5 \%)$. Families with children under the age of 18 were more likely to be working poor $(9.4 \%$ compared to $2.2 \%$ without children), as were families with only one employed person ( $12.5 \%$ compared to $1.8 \%$ with two or more workers).

To define the working poor the BLS uses criteria that could be viewed as arbitrary or insufficient. Recent research indicates that the official poverty level is too low (Short and Garner 2002) and many researchers use a higher level, typically 150 to 200 percent of the official poverty level. There is also variation in the amount of work needed to be considered as "working." Some research divides the working poor into two groups: those working full-time full-year, and those working either part-time or part-year. This research consistently shows that the working poor, compared to higher income workers, are less likely to have health insurance coverage of any type (public or private), to have 
less access to care, and to have poorer health (Seccombe 1996, Guendelman and Pearl 2001 and Zagorsky 1999).

Seccombe (1996) uses data from the 1977 National Medical Care Expenditure Survey and the 1987 National Medical Expenditure Survey, both predecessors of the MEPS, to show that health insurance coverage differs across socioeconomic groups, and that the uninsured rate among the working poor increased more than other groups between these two time periods. Seccombe (1996) uses three income categories; below the official poverty level, the poverty level to 200 percent of poverty, and above 200 percent of poverty, which she calls the poor, the economically vulnerable and the nonpoor, respectively. In addition to income status, six socio-demographic variables and two work place variables are used; education level, age, sex, race/ethnicity, marital status, rural/urban residence, and dummy variables for occupation and industry codes. These variables are used in logistic regression models to predict the likelihood of having private health insurance or of being uninsured.

The results show that the uninsured rate was unchanged over this time period for the non-poor, but the working poor and the economically vulnerable had increases of 56 and 45 percent, respectively. In 1987 about half of the working poor and more than a third of the economically vulnerable were uninsured, while 8 percent of the non-poor were uninsured. Regarding private coverage, the working poor and the economically vulnerable had declines in coverage by 26 and 10 percent respectively, while the nonpoor had a three percent increase in coverage (from 89 to 92 percent). The declines in private coverage, and the increase in the uninsured rate, for the working poor and the economically vulnerable, were across all subgroups, except for poor clerical workers, 
who had private coverage increase by 36 percent. After controlling for demographic and occupational characteristics, the working poor were 4.5 times more likely than the working non-poor to be uninsured. Persons with no more than a high school diploma, under the age of 35 , single, or a minority, were more likely to be uninsured, while women were less likely. There were no rural/urban differences.

Guendelman and Pearl (2001) use data from the 1997 National Health Interview Survey (NHIS) to examine access to care for the children of the working poor. The NHIS is a nationally representative survey sponsored by the National Center for Health Statistics. The 1997 NHIS collected data from 15,350 families with children, with a response rate of 88.9 percent. Guendelman and Pearl (2001) define poor families as those whose income is below 200 percent of the official poverty level. Three comparison groups are used: the working poor, the non-working poor, and non-poor working families. Descriptive statistics and multivariate logistic regression models are used to examine the differences between these groups. Overall, working poor families with children were three times more likely to be Hispanic and twice as likely to be black, as compared to higher income families.

Guendelman and Pearl (2001) find that 22.0 percent of the children in working poor families are uninsured, which is significantly higher than both the non-working poor and the non-poor working families ( $12.4 \%$ and $5.3 \%$ respectively). Children of the working poor are more likely to either delay care or not get care at all $(7.3 \%)$ than children in the comparison groups ( $4.4 \%$ and $2.7 \%$ for non-working poor and non-poor working families respectively). When broken-down by type of care, dental care was the primary source of delayed or missed care for the children of the working poor. There 
was no difference between the working poor and the non-working poor regarding their children having a regular source of care (90.4\% versus $91.0 \%$ respectively), but both were significantly below the non-poor working families (96.6\%). For children in less than excellent health, the children of the working poor were less likely to have had a doctor visit in the past 12 months ( $83.8 \%$ had at least one visit) than were the children of the non-working poor $(88.3 \%)$ or children of the non-poor working families $(90.9 \%)$. However, focusing on the differences between the working poor and the non-working poor, in the multivariate model, children of the working poor were not different from children of the non-working poor in terms of health care utilization, but were twice as likely to have disruptions in health insurance coverage. Regarding public assistance, 13 percent of the children of the working poor were enrolled in TANF, compared to 54 percent of the non-working poor, and 30.5 percent of the working poor were receiving public health insurance, compared to 77.8 percent of the non-working poor. There were no differences between the children of the comparison groups regarding age, sex, regional or rural vs. urban residence.

Zagorsky (1999), uses data from 1985 to 1995 from the National Longitudinal Survey of Youth 1979 (NLSY79) cohort to examine the characteristics of the working poor that have health limitations, drug or alcohol addictions, or language barriers. He finds that the working poor, as compared to the working non-poor, are more likely to have these problems. The NLSY79 is a nationally representative survey sponsored by the Bureau of Labor Statistics (BLS). The 1979 sample consisted of 14,574 persons aged 14 to 21 years old, and interviews of this sample have been conducted annually since then. 
The response rate in 1979 was 87 percent and this decreased each year to about 68 percent in 1994.

Zagorsky (1999) uses the official BLS definition to define the working poor.

Overall, from 1985 to $1995,7.0$ percent were classified as working poor, but among those with a health limitation, drug or alcohol problem or language barrier, 11.7 percent were working poor, compared to 5.8 percent without any of those problems. Among the working poor in 1995, 33.1 percent had at least one of these problems, compared to 20.6 percent of the working non-poor. Among the working poor with a health limitation, drug or alcohol problem or language barrier 76.9 percent either worked part-time or part-year, which indicates that these problems could be keeping them in poverty by limiting their amount of work. Over the course of the ten years examined in this study, some persons in the sample moved in and out of poverty, but those with any of the identified problems were much more likely to remain in poverty; 41.4 percent of the persons that were both poor and had one or more of these problems in 1985 were also poor in 1995. Overall, 30.5 percent of the cohort experienced at least one year of working poverty. Among those to ever experience being working poor during the 10 year period, they were more likely to be female than male, and less likely to have higher education; 53 percent were women compared to 47 percent men, and 2.4 percent had an advanced degree, compared to 49.0 percent with only a high school diploma. They are also more likely to be white overall, but within race blacks were more likely to have ever been working poor; blacks were 14.7 percent of the study population but 25.4 percent of those to have ever been working poor. 


\section{Summary}

The literature on the working poor shows that a significant percent of families are poor, despite having an employed person in the family. All of the research shows racial disparities, with blacks and Hispanics being at a greater risk of being working poor. The studies that examine health insurance, Seccombe (1996), and Guendelman and Pearl (2001), find that the working poor are more likely to be uninsured, as compared to higher income workers, and that the uninsured rate has increased over time. BLS Report 976 (2004), Seccombe (1996), and Zagorsky (1999) find that low levels of education are associated with an increased risk of being working poor. Women are more likely to be working poor than are men (BLS Report 976 (2004) and Zagorsky (1999)). Zagorsky (1999) finds that the working poor are in poorer health than higher income workers and that poor health keeps some of the working poor in poverty. Guendelman and Pearl (2001), the only study to examine the difference between the working poor and the nonworking poor, in the context of access to care, finds that the children of the working poor have less access to care and are more likely to delay or not get care at all, than the children of the non-working poor, or higher income families.

\subsection{Welfare Reform}

Prior to 1996 the New Deal social contract included entitlement programs that provided cash assistance and health insurance to persons that met certain eligibility requirements. These programs greatly expanded health insurance coverage and helped offset OOP health care expenditures for the poorest persons. During the "Great Society" movement of the 1960 s entitlement programs were expanded due to the public awareness of widespread poverty in America, primarily through the book "The Other America: 
Poverty in the United States" by Michael Harrington, published in 1962 (Harrington

1962). These programs did not have any limits regarding how long a person could receive benefits, but it was assumed that the benefits would be temporary until the recipients could find employment, or receive job training that would lead to employment (Patterson 2000).

However, there was a disincentive to work for persons receiving welfare benefits. Benefits could be cut off as soon as employment began, and the potential loss of health insurance was a serious concern to recipients, especially those with children. Beginning in the late 1960s there was a sharp increase in the number of persons receiving welfare benefits, and the rapidly increasing cost of these benefits, combined with a recession in the early 1970s, gave rise to the notion of a welfare crisis (O'Connor 1998). This prompted a series of program and policy changes designed to encourage persons on welfare to enter the labor force. ${ }^{1}$

The most significant policy change to date, the Personal Responsibility and Work Opportunity Reconciliation Act (PRWORA) of 1996, ended welfare policies that had been in place since the Social Security Act of 1935. Aid to Families with Dependent Children (AFDC), the main welfare program, was replaced with Temporary Assistance to Needy Families (TANF), which set a maximum of five years lifetime limit on cash benefits and stipulated work requirements. This Act is the most far reaching Federal

\footnotetext{
${ }^{1}$ For example, income disregards allowed some income from work, without a reduction in AFDC benefits which had the effect of raising the eligibility threshold and caused the AFDC rolls to increase significantly. Various job training programs targeted at welfare recipients have come and gone without much success. The Earned Income Tax Credit (EITC), enacted in 1975 and ongoing, is widely considered a success in raising the income of low wage workers. The EITC allows low income tax filers to reduce their Federal tax liability and can result in a significant refund, even when no taxes are owed. The EITC can be viewed as a wage subsidy for low income workers. Hotz, et al (2001) has shown that the EITC is effective in motivating some welfare recipients to join the labor force.
} 
policy to date to try to move people off of welfare and into the workforce, and it has been remarkably successful in that regard, reducing case loads by 56 percent by the year $2000 .^{2}$ However, not all of those removed from the welfare rolls were removed because of employment; time limits and sanctions have removed recipients as well. As a result of the PRWORA, welfare is no longer something that a person is entitled to in America, regardless of their need.

Karger (2003) argues that welfare policy has been transformed into labor policy and that administration of the PRWORA should be moved from the Department of Health and Human Services to the Department of Labor. Karger (2003) describes how conservatives have fought against welfare policies since 1935, and that the PRWORA is the climax of this struggle. He states that the cost of the programs were never their real concern, since AFDC and Food Stamps combined were just three percent of the federal budget in 1995. Their real objection was philosophical rather than fiscal. They never accepted the premise of public assistance, that the labor market was not capable of providing for the financial needs of anyone willing to work.

Through conservative efforts, welfare to work programs began in 1967, but they were never adequately funded, and most were deemed failures. Research evaluating the effectiveness of these programs by the Manpower Development Research Corporation found only two that were effective and they cost over $\$ 5,000$ per participant (Gueron and Pauly 1991). There was never the political will to commit the funds necessary for an effective welfare to work program. Conservatives retook control of congress in 1994 at a

\footnotetext{
${ }^{2}$ According to the Department of Health and Human Services, from 1993 to 2000 there was a 56 percent reduction in the number of families receiving AFDC/TANF. The reduction in caseloads began in 1993 when some states were exempted from AFDC rules and allowed to experiment in ways to move welfare recipients into the labor force (Loprest et al. 1999).
} 
time when the American economy was very strong, which helped fuel the notion that there was a job out there for anyone willing to work, and they were determined to eliminate the New Deal social contract. President Clinton, a Democrat, supported a gentler version of welfare reform but, for political reasons, was forced to sign into law a harsh version crafted by the conservative Republicans. Under the new law, after the poor have exhausted their benefits they become a labor market problem rather than a welfare problem.

There have been many studies that examine the impact of the PRWORA; Loprest and Zedlewski 1999, Kaplan et al. 2005, Acs, Loprest and Roberts 2001, and Lindhorst and Mancoske 2006, just to cite a few. One of the first studies was conducted by Loprest and Zedlewski (1999) of the Urban Institute (Loprest and Zedlewski 1999). Using data from the 1997 National Survey of America's Families (NSAF), just one year after the passage of the PRWORA, Loprest and Zedlewski (1999) examined the demographic differences between former and current welfare recipients. The NSAF, sponsored by the Urban Institute, is a nationally representative survey using a dual-frame methodology consisting of Random Digit Dialing (RDD) telephone interviews and an area sample using in-person interviews. The 1997 NSAF conducted interviews at more than 44,000 households with an overall response rate of about 70 percent.

Loprest and Zedlewski (1999) found that current welfare recipients, compared to former welfare recipients, were more likely to be Hispanic, have less education, less likely to be married, more likely to live in the northeastern and western regions of the country and have more obstacles to finding work. Regarding age, the only significant difference is in the age category 51 to 65 years old, with current recipients more likely to 
be in this category than former recipients ( $4.6 \%$ versus $1.9 \%)$. About 70 percent of current recipients were less than 35 years old. The biggest difference they found was in the number of obstacles to work. Previous research by Zedlewski (1999) had identified six characteristics that are obstacles to welfare recipients finding work; 1) lacking at least a high school education, 2) a long period of unemployment, 3) having a child less than one year old, 4) having a child that receives Supplemental Security Income, 5) limited English speaking ability and 6) poor physical or mental health. They find that 42 percent of former welfare recipients had none of these obstacles compared to only 23 percent of current welfare recipients. The most significant differences in obstacles to work were in education and work experience, with current welfare recipients much more likely to have less than a high school education ( $41 \%$ versus $29 \%$ ) and more likely to have never worked or last worked three or more years ago ( $43 \%$ versus $13 \%)$. There were no differences between current and former welfare recipients with regards to having a child less than one year old, limited English speaking ability, or health status.

However, other studies have found health differences between welfare recipients and non-recipients. Kaplan et al. (2005) used data from the Woman's Employment Study (WES) to examine the health of women on welfare, compared to women not receiving welfare. Kaplan et al. (2005) find that women on welfare are less healthy than women not on welfare. The WES is a random sample of 753 single mothers on welfare in Michigan in 1997. Four face-to-face interviews were conducted from 1997 to 2001 with an overall response rate of 66 percent. In the third wave (in 2000), in addition to questions about their health, physical measures were taken which included blood pressure, peak expiratory flow and body measurements. These data were compared to 
similar data for comparable women not on welfare from the 1999-2000 National Health and Nutrition Examination Survey (NHANES), a nationally representative survey conducted by the National Center for Health Statistics.

Compared to women in the NHANES women in the WES were more likely to be black ( $53 \%$ versus $16 \%$ ). They found that women in the WES sample were 1.35 times more likely to have ever smoked and nearly twice as likely to be current smokers. The body mass index (BMI) of women in the WES sample was 16 percent greater, with obesity among white women nearly twice that of white women in the NHANES sample. Nine percent of the women in the NHANES sample had hypertension, compared to 22 percent in the WES sample. Women in the WES sample were also more likely to have diabetes, arthritis and were more likely to describe their overall health as fair or poor. Regarding health insurance coverage, over the course of the study, the percent of women in the WES sample that were uninsured increased from 6.8 percent in 1997 to 21 percent in 2001.

In 1998, in an effort to understand the impact the PRWORA was having on former welfare recipients (referred to as "leavers"), the Office of the Assistant Secretary for Planning and Evaluation of the Department of Health and Human Services awarded grants to several state and county governments to perform studies of leavers to examine their well-being. These studies used both administrative records and survey data from a sample of leavers. Acs et al. (2001) summarized the results of 15 of these studies. The studies show that about 75 percent of welfare leavers had at least some employment in the year after leaving welfare and about a third worked for the entire year. Average wages were about $\$ 7.50$ an hour, which left most leaver families in poverty. They find 
that about half of employed leavers were offered employer sponsored health insurance, but only a third take-up the coverage, and about half of working leavers had paid sick leave.

Regarding barriers to work, the studies varied significantly, ranging from 6 to 25 percent of leavers having to overcome problems with transportation, child care or personal health issues. It is common for leavers to return to welfare; across all studies between 25 to 33 percent of all leavers retuned to TANF in the year after leaving. Most leaver families continue to need some form of public assistance, with about 67 percent receiving food stamps at some point during their first year and about 60 percent having at least one adult receiving Medicaid. Four of the studies found that leavers report being less able to afford health care for their family after leaving welfare. Between 10 to 40 percent of leaver families had an uninsured adult, and between 10 to 25 percent of leaver families had an uninsured child. Five to ten percent reported a child in poor health.

Nationally, by 2002 about 93,000 families had been forced off of TANF due to time limits. To examine the impact of being forced off TANF through time limits and sanctions, Lindhorst and Mancoske (2006) examined data from a three wave panel study of TANF recipients from 1998 to 2001 in Louisiana. The sample size was 570 single mothers living in Louisiana and receiving TANF benefits in 1998. The cumulative response rate at wave two, from which much of the analysis is drawn, was 61.1 percent. By wave three the response rate was 48.6 percent.

Louisiana has one of the strictest time limit and sanctions policies of all the states, with cash benefits lasting only two years, rather than the five year maximum limit imposed by the Federal Government. In 1999 4,200 persons in Louisiana were removed 
from the welfare rolls due to time limits. Louisiana also is one of just a few states that use a full family sanction where benefits are withheld from the entire family if the qualifying adult fails to meet their obligations under TANF. In their analysis the dependent variable is TANF status and has the following four categories: 1) currently receiving TANF, 2) voluntary leavers -- those persons that left TANF voluntarily due to employment or marriage, 3) timed-off leavers, and 4) sanctioned leavers. The analysis used descriptive statistics, multinomial logistic regression and analysis of variance to determine the differences between these categories.

By the end of the second year of the study 62 percent of the sample had left TANF. Among those that left, 54 percent were voluntarily leavers, 21.8 percent were timed-off leavers and 24.2 percent were sanctioned leavers. Compared to persons remaining on TANF, sanctioned leavers were not different on most of the characteristics examined, which were, age, race, has a child less than 5 years old, rural residence, currently employed, ever married, disabled recipient, disabled child, victim of domestic violence, recent poverty, or childhood poverty. Both timed-off and voluntary leavers, compared to current recipients, were about half as likely to have a child less than 5 years old, and more than three times as likely to be currently employed. Voluntary leavers had the highest work rate with about 50 percent employed while only a third of timed-off leavers were employed. Timed-off leavers were about one quarter as likely to have a disabled child.

The study also measured financial resources and material hardships and found that timed-off leavers had significantly lower monthly income than the other groups; about $\$ 6,608$ a year, which is nearly 50 percent of the poverty level for one adult and two 
children. TANF recipients had the highest monthly income of all the groups, and were also more likely than voluntary leavers to be receiving food stamps. Across all groups nearly a third reported food insecurity and housing problems, but the differences between the groups was not significant. Compared to current TANF recipients, all of the leavers were three times more likely to report being unable to obtain needed medical care for an adult in the family, and to need Medicaid but unable to obtain it. In their conclusion Lindhorst and Mancoske (2006) note that the goal of the current welfare policy is for recipients to provide for their own support through participation in the labor market, yet not even one third of the leavers in this study were employed and a third or more reported food insecurity, housing problems, and going without needed medical care.

\section{Summary}

Only one of the welfare reform studies presented here, Loprest and Zedlewski (1999), uses nationally representative data, and it is a potential limitation of the other studies that their data is not nationally representative. Loprest and Zedlewski (1999) find that current welfare recipients are more likely to be Hispanic, whereas Kaplan et al. (2005) find that current welfare recipients are more likely to be black. Regarding age, education and marital status, Loprest and Zedlewski (1999) find that the distribution of age between current and former welfare recipients only differs significantly for older persons, but overall 70 percent of current recipients were less than 35 years old; current recipients were more likely to have less than high school as their highest level of education and less likely to be married.

Regarding barriers or obstacles to work, Loprest and Zedlewski (1999) find that having a low level of education or lacking work experience were the most significant 
obstacles, but Acs et al. (2001) find that transportation, child care and personal health problems are the most significant barriers to work. The studies that examine health insurance, Kaplan et al. (2005), Acs et al. (2001), and Lindhorst and Mancoske (2006) find that former welfare recipients are more likely to be uninsured, and Acs et al. (2001) and Lindhorst and Mancoske (2006) find they are more likely to have difficulty getting needed medical care. Although Loprest and Zedlewski (1999) do not find any health differences between current and former welfare recipients, Kaplan et al. (2005) find that women on welfare are less healthy than women not on welfare, and Acs et al. (2001) find a significant portion of former welfare recipients reporting having to overcome health problems to enter the labor market. The two studies that examine the employment characteristics of former welfare recipients, Acs et al. (2001), and Lindhorst and Mancoske (2006), do not find evidence that employment has improved their circumstances, and Lindhorst and Mancoske (2006) find that they are worse off than current recipients.

\subsection{Literature Review Summary}

The previous literature on health care expenditures, the working poor, and welfare reform casts doubt on the ability of the labor market to provide adequate employment to the poor, especially with respect to health care and health care expenditures. Although health care expenditures are concentrated in persons in poor health, the majority of families with a high financial burden due to OOP health care expenditures incur this burden not because the expenditure is large in absolute terms, but because their income is low, so that the expenditure is large relative to their income. Because of this the poor spend a disproportionately higher share of their income for health care than all other 
income groups. Among the poor, employment is not shown to increase their access to care, and may in fact have the opposite effect.

When examined at the family level, OOP health care expenditures are measured several different ways in this research with the most common being the percentage of total family income that is used to pay the OOP health care expenses for the family. This measures the financial burden that health care expenditures create for the family. Since it is highly skewed, this measure is typically categorized, or dichotomized, with 5, 10 and 20 percent being typical. Health insurance premiums are considered a health care expenditure. Two of the studies reviewed here exclude premiums and one included them.

This research shows that the poor are more likely to be uninsured, but within the poverty population the working poor are more likely to be uninsured than the nonworking poor, and the uninsured rate among the working poor has been increasing over time. An unexpected finding in this research is that the uninsured poor have a health care financial burden less than that of the insured poor. If having health insurance protects against high OOP health care expenditures it would be reasonable to expect the uninsured poor to have a financial burden greater than the insured poor. However, health insurance also provides access to care, especially preventative care, which the uninsured are likely to go without because of the cost. Galbraith et al. (2005) find that the uninsured poor have significantly fewer doctor visits than the insured poor, and this difference in access to care may explain why the uninsured poor have a lower financial burden; the uninsured poor may compensate for their lack of health insurance by consuming less health care.

The research on welfare reform consistently shows that families are worse off after leaving welfare. The underlying rationale of the PRWORA, that families can better 
provide for themselves through participation in the labor market than they can by being on welfare, is shown to be dubious. The only research to examine the effect of employment on the financial burden of OOP health care expenditures (Wyszewianski 1986) found that employed families, compared to unemployed families, were slightly less likely to have a burden equal to or exceeding 20 percent. However, this was not a multivariate finding which could control for the other covariates of burden, and the family level employment measure Wyszewianski (1986) used may underestimate total family employment. If the comparison of current welfare recipients to former welfare recipients can be taken as a proxy for the comparison of the non-working poor to the working poor, then the conclusion would be that the working poor are worse off than the non-working poor. However, this is not entirely accurate because many former welfare recipients are not working, and a small percent of welfare recipients have some employment. The underlying rationale of the PRWORA may be dubious, but it is not decisively shown to be false by this research, at least not with respect to OOP health care expenditures. The impact of employment on OOP health care expenditures remains unexamined in a rigorous way.

This thesis provides evidence on this issue by examining the relationship between employment for poor families and their ability to afford health care. In particular, this thesis will compare the health care financial burden of the working poor to the nonworking poor. This question has not been previously examined using multivariate analysis and the potential effect of employment on health care burdens among the poor is not easy to determine. The working poor have a higher income than the non-working poor, which, with all other things being equal, would reduce their burden compared to the 
non-working poor. However, there are a number of other differences between these groups which are likely to affect their relative burdens. The working poor are more likely to be uninsured, which will increase their health care burdens, unless they compensate by reducing their use of health care. The non-working poor are likely to be in poorer health, which would tend to increase their health care burdens, but they are also more likely to have public health insurance, which offers the greatest protection from OOP health care expenditures. This issue is complex and the only way to determine the effect of employment on the financial burden of OOP health care expenditures is to use multivariate analysis, controlling for the other covariates of burden. The next section presents the formal hypotheses and two research questions.

\subsection{Hypotheses and Research Questions}

This thesis seeks to contribute to the research on the adequacy of the labor market by focusing on the relationship between employment and OOP health care expenditures for poor families. The following null and alternative hypotheses will be tested:

$\mathrm{H}_{0}$ : Employment for the poor is not associated with their level of health care expenditure burden.

$\mathrm{H}_{\mathrm{a}}$ : Employment for the poor is associated with their level of health care expenditure burden.

In addition, the following two research questions will be examined:

1) Does employment for the poor have a differential impact on the probability of having a high OOP health care burden ( $10 \%$ of family income) vs. a very high burden ( $20 \%$ of family income)?

2) Is the estimated relationship between employment and OOP health care burden sensitive to the type of employment measure used? 


\section{CHAPTER 3}

\section{METHODS}

Multivariate analysis will be used to estimate the association of employment and the financial burden of OOP health care expenditures for poor families, while controlling for the other covariates of burden. Previous research indicates that income, health status and health insurance status are the best predictors of financial burden, but demographic variables such as age, education, sex and race may also be important. Both linear regression models and logistic regression models could be used for this analysis, but there are potential problems with linear regression, and analytical advantages with logistic regression. The justification for using logistic regression for the multivariate analysis is presented in section 3.4 .

The following sections will describe the data source, target population, dependent variable, multivariate model, and the independent variables, including the interaction terms.

\subsection{Data Source}

The 2002 Medical Expenditure Panel Survey (MEPS) will be used for this analysis. The MEPS, a nationally representative survey of the U.S. civilian noninstitutionalized population, collects medical expenditure data at both the person and household levels. The MEPS collects detailed data on demographic characteristics, health

\footnotetext{
${ }^{3}$ This section is taken directly, with only a few minor changes, from the MEPS 2002 Full Year Consolidated Data File documentation, available on the MEPS website at http://www.meps.ahrq.gov/PUFFiles/H70/H70doc.htm
} 
conditions, health status, use of medical care services, charges and payments, access to care, satisfaction with care, health insurance coverage, income, and employment. The MEPS is cosponsored by the Agency for Healthcare Research and Quality (AHRQ) and the National Center for Health Statistics (NCHS). The MEPS is the best nationally representative source of health care expenditure data available.

The MEPS uses an overlapping panel design, shown in figure 1, in which data are collected through a preliminary contact followed by a series of five rounds of face-to-face interviews over a $2 \frac{1}{2}$-year period. Using computer-assisted personal interviewing (CAPI) technology, data on medical expenditures and use for two calendar years are collected from each household. This series of data collection rounds is launched each subsequent year on a new sample of households to provide overlapping panels of survey data and, when combined with other ongoing panels, will provide continuous and current estimates of health care expenditures. The 2002 data were collected in Rounds 1, 2, and 3 for MEPS Panel 7 and Rounds 3, 4, and 5 for MEPS Panel 6. (Note that Round 3 for a MEPS panel is designed to overlap two calendar years.)

The sampling frame for the MEPS Household Component is drawn from respondents to the National Health Interview Survey (NHIS). The NHIS is a crosssectional household interview survey. The sampling plan follows a multistage area probability design that permits the representative sampling of households. The first stage consists of a sample of 358 primary sampling units (PSUs) drawn from approximately 1,900 geographically defined PSU's that cover the 50 states and the District of Columbia. A PSU consists of a county, a small group of contiguous counties, or a metropolitan statistical area. 
Within a PSU, two types of second-stage units are selected; area segments and permit area segments. Area segments are defined geographically and contain an expected 8 or 12 addresses. Permit area segments cover geographical areas containing housing units built after the 1990 census. The permit area segments are defined using updated lists of building permits issued in the PSU since 1990 and contain an expected four addresses. Within each segment all occupied households at the sample addresses are targeted for interview.

The 2002 MEPS contains data associated with 39,165 persons. These persons received a person-level weight, a family-level weight, or both. Of these persons, 37,418 were assigned a positive person-level weight. There were 15,051 families receiving a positive family-level weight. The overall response rate was 64.7 percent.

I have worked at AHRQ, and specifically on the MEPS, since June 2001. While nearly all of the data used for this thesis is public use data, I have access to data not available to the general public. The only non-public data used in this thesis is a modified family income variable and OOP health insurance premiums. The public use data has before-tax income, however, Dr. Tom Selden and Dr. Didem Bernard, researchers at AHRQ, using complex simulation models, have created an after-tax income variable which I have used in this thesis (Selden and Bernard 2004).

\subsection{Target Population}

In this thesis I will focus on non-elderly poor families. This sub-set of our population is vulnerable to the rapidly rising cost of health care, as well as social safety net and health care policy changes at the state and federal level. However, the concept of "poor" is subjective and can be defined in different ways. For this thesis I define "poor" 
as those families with family incomes up to 125 percent of the official poverty level. The definition of family is that used by the Current Population Survey and includes single person "families."

According to the Census Bureau, in 20029.6 percent of all families were poor. Using the higher threshold of 125 percent of the official level, I estimate that 13.2 percent of all families were poor in 2002. "Student families," defined as a family consisting entirely of persons 18 to 24 years old whose main activity in 2002 was attending school, are not included since they do not represent typical families. Also, "elderly families," defined as a family consisting entirely of persons 65 years old or older, are not included since they are nearly all covered by Medicare, and most are no longer in the labor force. Families that include a mix of persons 65 and older and persons less than 65 years old are included. This leaves 2,770 poverty families representing 18.0 million families (17.4 percent of all families) in the United States that will be used for the analysis. Table 1 shows the distribution of all families by income status, excluding "student families" and "elderly families."

\subsection{Dependent Variable: Health Care Expenditures Burden}

The dependent variable in this analysis is the financial burden created by OOP health care expenditures. OOP health care expenditures, as measured by the MEPS, include expenditures for medical provider visits, hospital inpatient stays and outpatient visits, emergency room visits, dental care, prescription medications, and medical equipment, which includes such things as prescription glasses and diabetic supplies. The MEPS does not capture purchases of over-the-counter medical products, so these are not included in OOP totals. OOP health insurance premiums, the amount paid by the 
family, are included in the OOP total health care expenditure. OOP health insurance premiums can vary significantly depending on whether the policy is public, private group, or private non-group. For poverty families with health insurance in the 2002 MEPS, annual premiums range from $\$ 0$ to $\$ 14,333$. Families with private non-group health insurance policies, on average, pay more than twice the OOP premium of a family private group plan ( $\$ 344$ per month vs. $\$ 149$ per month). Health insurance premium data is not widely available and it is a significant analytical advantage to have it for this analysis.

Figure 2 shows the distribution of OOP health care expenditures for poverty families in 2002. Each bar in the figure represents the percentage of families in a given $\$ 500$ interval where the first interval is $\$ 0$ to $\$ 499$, the last interval is $\$ 2,500$ or more and all expenditures are expressed in 2002 U.S. dollars. Nearly 55 percent of all poverty families have an expenditure of less than $\$ 500$ and about 13 percent spent $\$ 2,500$ or more on health care. The mean expenditure is $\$ 1,166$ and the median is $\$ 375$. Since most families have relatively small OOP health care expenditures the measure is highly skewed.

The ability to pay OOP health care expenditures is a function of total family income. Sources of income for the non-working poor include income from welfare, including cash payments, food stamps, or rent assistance, and cash support from relatives. Income for the non-working poor also includes employment income. The Bureau of Labor Statistics (BLS) defines the working poor as those families that had at least 27 weeks of employment during the year. Under this definition the "non-working" poor can have up to 26 weeks of employment during the year. 
Figure 3 shows the distribution of total family income of poverty families. Each bar in the figure shows the percentage of families in a given $\$ 5,000$ interval, where the first interval is $\$ 0$ to $\$ 4,999$ and the last interval is $\$ 25,000$ or more. Slightly more than 65 percent of poor families earn less than $\$ 10,000$ and only 3.1 percent earn $\$ 25,000$ or more. The mean income is $\$ 9,409$ and the median is $\$ 8,233$.

The absolute amount of money spent for health care is less informative than the expenditure relative to income, called the expenditure burden. This is obtained by dividing the total family OOP health care expenditure by total family income. Figure 4 shows the skewed distribution of this measure in five percent intervals where the first interval is 0 to 4.9 percent and the last interval is 20 percent or more. About half of all poverty families have an expenditure that consumed less than 5 percent of their income and about 37 percent spent 10 percent or more or their income on health care, a level considered to be high (Banthin and Bernard 2006). The distribution resembles the distribution of health care expenditures in figure 2 .

In creating this measure of health care burden I used a number of edits which were designed to make the measure more meaningful and less susceptible to reporting and other measurement error. First, the income data was edited so that all families had at least $\$ 1,000$ income. This edit affected 307 cases, nearly all of them with less than seven months of work. This assures that any family identified as having a high financial burden had at least $\$ 100$ of OOP health care expenditures. For example, there was one family that reported $\$ 20$ income and $\$ 10$ OOP health care expenditure. Without this edit this family would be flagged as having a very high burden, when their OOP expenditure was trivial. Also, it is unlikely that the reported $\$ 20$ total family income is accurate. This edit 
was developed in consultation with Dr. Selden at AHRQ, who oversees the editing of the MEPS income data and is one of the agency experts on health care expenditures. Income will not be an independent variable in this analysis since it is used in the creation of the dependent variable.

The mean of the expenditure burden measure is 33.6 percent while the median is only 5.0 percent. Outliers have pulled the mean up beyond what would be expected, given that half of poor families had no more than a five percent expenditure burden. The most extreme outlier is a family that had total family income of $\$ 1,000$ and $\$ 73,358$ of total family OOP health care expenditures, or 7,336 percent of income spent on health care. Using savings and other assets, it is possible for a family to spend all, or more, of their annual income for health care. While cases like this are outliers, they are possible values, which make editing them somewhat arbitrary.

Rather than trying to edit the outliers, new measures can be created to reduce their impact on burden estimates. One approach is to dichotomize the distribution at a point that makes analytical sense. This is a common way of treating expenditure burden data, and levels of $1 / 2,5,10,15$ and 20 percent have been used, with 10 and 20 percent being the most common (Banthin and Bernard 2006). For this thesis two "dummy" variables are created, one to identify families that spent 10 percent or more of their family income on health care, and another to identify families that spent 20 percent or more. These variables overlap and therefore are not mutually exclusive. The assumption with these measures is that a health care expenditure of 10 percent or more of family income is a high financial burden on the family, while an expenditure of 20 percent or more is a very 
high financial burden. Using these measures I find that in 200237.4 percent of all poverty families had a high burden and 23.2 percent had a very high burden.

Table 2 shows the cross-tabulation of the two burden measures. The cell with high burden equal "no" and very high burden equal "yes" is empty because all families with a very high burden also have a high burden. The table shows that 62.1 percent of families with a high burden also have a very high burden. Overall, 62.6 percent of all poverty families have neither a high nor very high burden.

Another way of dealing with skewed data, and reduce the impact of outliers, is to normalize it by performing a natural $\log$ transformation. $\log (0)$ is undefined, so those families with zero percent of income spent on OOP health care expenditures are edited and given one percent. As the probability density curves in Figure 5 show, the natural $\log$ transformation of the burden measure is relatively normally distributed. Although Figure 5 seems to suggest that the log transformation is a useful approach here, I decided not to use it for reasons explained in the following section.

\subsection{Multivariate Model:}

Regression models will be used to estimate the association of employment and the financial burden of OOP health care expenditures for poor families, while controlling for the other covariates of burden. As noted in the previous section, the burden measure is highly skewed. Two possible ways to deal with skewed data are to perform a natural log transformation to normalize it, and then run an OLS regression model, or to dichotomize it and run a logistic regression model.

Performing a natural log transformation on burden and using OLS regression is not a good choice for this analysis for a couple of reasons. First, I am not seeking to 
understand the overall effect of employment on burden, but rather the impact of employment on the probability of having specific high levels of burden. Second, to be meaningful to policymakers, and others, results from models that use the natural log of burden must be retransformed back into the original scale. However, the error terms in natural log models of health economic data are typically heteroscedastic in one or more of the covariates, which can result in biased estimates on the raw scale (Manning, Basu and Mullahy 2005). For these reasons OLS regression will not be used.

Two logistic regression models will be used for the multivariate analysis, one to estimate the association of employment and the financial burden of OOP health care expenditures for poor families with a 10 percent burden, and one to estimate the association of employment and the financial burden of OOP health care expenditures for poor families with a 20 percent burden. Since the two dichotomized burden measures overlap, and therefore are not mutually exclusive, multiple logistic regression cannot be used. Multinomial logistic regression could be used if the continuous burden measure were trichotomized rather than dichotomized. In that case three mutually exclusive burden levels would be set at less than 10 percent, 10 percent to less than 20 percent, and 20 percent or more. However, that is a fundamentally different measurement and does not measure what I want for this analysis. The analysis could be simplified by using one dichotomous measure of burden. However, the existing literature does not universally agree upon what constitutes a high level of OOP expenditure burden. Several different levels have been used, with 10 and 20 percent being the most common (for example, see Banthin and Bernard 2006). 
The statistical software STATA will be used to run the logistic regression models. STATA has the ability to correctly adjust the standard errors for the complex sample design of the MEPS. The basic form of the model is shown below:

Prob $($ Burden $)=\beta_{0}+\beta_{1} *$ Employment Status $+\beta_{2} *$ Demographics $+\beta_{3} *$ Access to Care $+\beta_{4} *$ Health Status + E

All variables are defined at the family level. Burden is a $0 / 1$ variable that indicates whether each family had a high financial burden created by OOP health care expenditures. Employment status is the main independent variable of interest. Models also include sets of variables that control for demographic, access to care and health status variables. Furthermore, access to care and health status are defined separately for adults and children. $\mathrm{E}$ is the error term and is not assumed to be normally distributed, but is assumed to be independent. The independent variables are discussed in greater detail in the following section.

\subsubsection{Independent Variables:}

The literature review provides very good guidance in choosing the independent variables. Income, health status, health insurance status, and other demographic variables were shown to be important predictors of burden. Income is used in the denominator of the dependent variable and will thus not be used as an independent variable.

Because employment status is the main independent variable in this thesis it receives a full explanation in the following section. The other independent variables will only be outlined.

\subsubsection{Employment Status:}

The goal of this thesis is to determine the effect of employment on the financial burden of OOP health care expenditures, while controlling for the effect of the other 
covariates of burden. Detailed employment data, including starting and ending dates for all jobs held, is collected for each person 16 years old and older in each round of the MEPS. This allows for an accurate measure of employment for the entire year.

According to the BLS a family must have at least one person 16 years old or older with at least 27 weeks of work, or looking for work, during the year to be counted as a "working family." For this thesis I identify a family as a "working family" if the combined employment of all persons 16 years old or older was at least seven months or more during the year, not including looking for work, which is similar to the BLS definition. I do not strictly adhere to the BLS definition because looking for work is not equivalent to working, and the point of this thesis is to determine the effect of employment on the financial burden of OOP health care expenditures. Also, for this analysis, two family members with combined employment of 7 months or more is equivalent to a single person with 7 months or more of employment. I use 7 months of employment (approximately 28 weeks) rather than 27 weeks because manipulating the MEPS employment data to measure employment in weeks rather than months would require considerably more programming effort, and would likely have little, if any, effect on the outcome of the analysis.

Figure 6 shows the distribution of employment using the modified BLS definition. The figure shows that poor families are almost evenly divided between the working and non-working categories.

Although the BLS defines the working poor as having nearly 7 months of employment during the year, this definition may not accurately reflect the distribution of annual employment and could be somewhat arbitrary. Figure 7 shows the probability 
density curve for the annual number of months worked by all family members. The distribution is tri-modal, with peaks at 0,12 and 24 months. For a family to have more than 12 months of work during the year there must be at least two workers in the family, since one family member can contribute at most 12 months of work. Figure 8 shows the distribution of the number of months worked for poverty families categorized into four categories.

To help gain a fuller understanding of the impact of employment on burden two sets of logistic regression models will be run, each set using a different employment measure; one dichotomized and closely aligned to the BLS definition of a working family, and another using the four categories shown in figure 8 . When entered into the multivariate model, the four categories in figure 8 will be entered as dichotomous variables, one for each category, with zero months excluded as the reference category.

\subsubsection{Demographic Variables:}

The demographic variables used in this analysis are shown in table 3. Galbraith et al. (2005) used these demographic control variables, which they called predisposing variables. All of the dichotomous variables are coded as $1=$ yes and $0=$ no. The two nominal variables, race and region, and the ordinal variables, age of the head-ofhousehold, highest level of education of any family member and family size, will be entered into the multivariate model as a set of dichotomous variables, one for each category, with one reference category excluded.

In creating the family level race variable, there were not enough mixed race families to construct a separate category, so they were coded into one of the three races, 
Hispanic, black or white/other, based upon the mix of races in the family. Asians were also too small a category and are included in the white/other category.

\subsubsection{Access to Care Variables:}

The access to care variables are shown in table 4 . Because there are health insurance programs that specifically target children, especially children from low income families, access to care will be measured separately for children and adults. In the multivariate model health insurance status will be entered as a set of dichotomous variables, one for each category, with one category excluded. The percents reported in table 4 for children were calculated by sub-setting to families with children.

\subsubsection{Health Status Variables:}

Adults in poor health tend to generate higher health care expenditures than do children in poor health. Therefore, health status will be measured separately for adults and children. Table 5 shows the health status variables used in this thesis. The percents reported for children were calculated by sub-setting to families with children.

\subsubsection{Interaction Terms:}

The literature does not provide much evidence of interactions terms. BLS Report 976 (2004) suggests an interaction between race and single parent families, and this will be the only interaction term, shown in table 6 . Although the majority of single parent households are headed by women, this variable includes all single parent households, including a few headed by men. The data shows that the problem of poor single parent families is greatest among black families. In the population of poor families overall, there are more white/other single parent families, but the percent of single parent families 
within race, and within race subset to families with children, shows that blacks have a much higher percent of families that are single parent families.

\subsection{Analytic Strategy:}

The procedure for fitting the logistic regression model will be a modified version of the steps described in the text Applied Logistic Regression by Hosmer and Lemeshow (2000). Below is an outline of this procedure as used in this thesis:

1) Run the multivariate model with all of the variables. Evaluate the significance of each variable and eliminate non-significant variables $(p>0.05)$ one at a time, rerunning the model each time. However, given the large number of variables in my model, I will eliminate two non-significant variables at a time. This is unlikely to change the final result. Variables known to be important in the literature may be left in the model even if they are not significant.

2) Add interaction terms to the model and evaluate their significance, keeping only significant terms.

3) Assess the fit of the model. Two goodness-of-fit measures will be used: 1) Area under the ROC curve (Receiver Operating Characteristic curve). This area is roughly equal to the proportion of times the model correctly predicts the actual outcome and ranges from 0.0 to 1.0 , with values of 0.7 or greater considered good and 2) HosmerLemeshow chi-square test -- the null hypothesis is that the model fits, so $p$-values greater than 0.05 are desirable. Also, although not a goodness-of-fit measure, the pseudo $R^{2}$ will be used to evaluate the model. Pseudo $R^{2}$ is similar to $R^{2}$ in linear regression, except the sum-of-squares is replaced with log-likelihoods. Values range from 0.0 to 1.0 and can be interpreted as the proportion of the variance in the 
dependent variable that is explained by the model. Values of 0.2 or greater are generally considered good for cross-sectional models with a limited dependent variable.

This procedure results in the most parsimonious model. A total of four models will be developed, two each for high burden and very high burden. For each burden measure the only difference in the two models will be how employment is measured, as described in section 3.5.1. The odds ratio will be used to determine which group has the greater odds of having a high or very high burden, and is easily calculated from the beta coefficients. STATA will provide odds ratios rather than beta coefficients upon request.

Additionally, the odds ratio of the employment measures will be compared across burden measures to see if the effect of employment on burden is different for the different levels of burden. In other words, is the effect of employment on high burden different from the effect of employment on very high burden? The literature does not address this issue and I assume that employment does not have a differential effect on the two burden measures. 


\section{CHAPTER 4}

\section{RESULTS}

The results section is comprised of three parts: bivariate results, multivariate results, and model evaluation.

\subsection{Bivariate Results:}

Before presenting the results of the multivariate analysis it will be useful to examine the relationship between the two burden measures and the independent variables individually. Since employment is the main independent variable its relationship will be examined closely, while the other independent variables will receive only a brief examination. Figure 9 shows the scatter plot of the percent of family income spent on OOP health care by the number of months worked for all family members. The general trend is for burden to be reduced as the number of months worked increases. The correlation between these two variables is -0.08 , which indicates a very weak negative relationship, with burden decreasing as the number of months worked increases.

Figure 10 shows the two burden measures by months worked, which has been dichotomized at 7 months and labeled "non-working" and "working." With the variables coded in this way the relationship appears much stronger. The correlation between employment status and both high burden and very high burden is -0.12 .

Figure 11 shows the two burden measures by months worked, where months worked has been categorized into four categories. This graph shows the same general 
trend as figure 10, with burden decreasing with increasing months of work. Figure 11 also shows an unexpected result regarding families with more than 12 months of work, with burden increasing for these families. However, the difference between families with 12 months of work and families with more than 12 months of work is not statistically significant, so no overall conclusions can be drawn from it.

This analysis of the relationship between the financial burden of OOP health care expenditures and months worked, without controlling for the other covariates of burden, suggests that as the number of months worked increases burden decreases, but at a decreasing rate, and may actually increase for families with more than 12 months of employment. Also, there is evidence that the relationship is not linear and if months worked were entered into the regression model as a continuous variable a transformation would need to be considered.

Table 7 shows the percent of poverty families with a high or very high burden for groups defined by the demographic variables to be used in this analysis. The percents shown are row percents with the complement excluded. For example, in the first row, 31.80 percent of working poor families have a high burden, so $100-31.80=68.20$ percent do not have a high burden, but this is not shown in the table. Asterisks indicate the results of the z-test comparing each category to the reference category for a given variable. Using the BLS-like definition, working families are less likely than nonworking families to have a high burden $(31.8 \%$ vs. $43.1 \%)$ or a very high burden $(18.0 \%$ vs. $28.5 \%$ ). The months of employment variable shows a similar result with the percent of families having either a high or very high burden being significantly higher for 
families with no employment, except for families with more than 12 months of employment and a high burden, which are not significantly different.

Regarding the age of the head-of-household, compared to households where the head-of-household is 18 to 24 years old, households with a head-of-household 45 to 64 years old, or 65 years old or older, were more likely to have both a high and very high burden. This result is corroborated by the variable indicating the presence of a person 65 years old or older in the family; 59.5 percent of families with a member 65 years old or older have a high burden, compared to 36.2 percent of families without a member 65 years old or older. Looking at the highest level of education for any family member, those families that had at least some college had significantly higher rates of both high and very high burden; 30.1 percent of families with less than high school had a high burden, compared to 57.8 percent of families with at least some college. Single parent families and families with at least one child less than 18 years old are less likely to have either a high or very high burden.

Female headed households and households with a married couple present are not different from male headed households or households lacking a married couple with regards to OOP health care expenditures burden. Regarding race, Hispanic and black families are much less likely to have either a high or very high burden, as compared to white/other families.

Families with three or more members are less likely to have either a high or very high burden, as compared to single person families ( $27.9 \%$ vs. $41.3 \%$ for high burden), while families with two members are not different from single person families. Families living in a MSA are less likely to have a high burden than families living in rural areas 
( $35.9 \%$ vs. $42.8 \%$ ), but are not different from rural families with respect to very high burden. Families living in the northeast and south are more likely to have a high burden than are families living in the west, but there are no regional differences for families with a very high burden.

Table 8 shows the percent of poverty families with a high or very high burden for groups defined by the access to care variables. Regarding health insurance status, for both children and adults, those families with private insurance had a significantly higher burden than families without private insurance (for example, $61.8 \%$ of families with an adult having private coverage had a high burden, compared to 27.2 percent of families with an adult having public coverage). For adults, the usual source of care variables and doctor visit variables behave as expected with families that report having no usual source of care, or no doctor visits, having significantly lower rates of burden, compared to families with a usual source of care or at least one doctor visit. For children, the results are not so straight-forward. For high burden the results for children are similar to adults, although weaker, but for those families with children and a very high burden there is no difference between those families with or without a usual source of care or doctor visits for the children.

Table 9 shows the percent of poverty families with a high or very high burden for groups defined by the health status variables. Families that have an adult with fair or poor health, or with a chronic health condition, are more likely to have a high or very high burden (for example, $46.4 \%$ of families that have an adult with a chronic health condition had a high burden, compared to $24.0 \%$ of families that do not have an adult with a chronic health condition). For families with children there is very little difference 
between those with a child having fair or poor health, or a chronic health condition and those having healthier children. The only significant finding is that families with a child with a chronic health condition are more likely to have a very high burden.

Table 10 shows the percent of poverty families with a high or very high burden for groups defined by the interaction terms. The percents in the table were calculated within race and sub-set to families with children. Hispanic and black single parent families are not significantly different from white/other single parent families with respect to the burden of OOP health care expenditures.

Although the focus of this thesis is the association of employment and the financial burden of OOP health care expenditures, it is useful to briefly examine the effect of employment on the components of burden, as well as the health insurance and access to care variables. As shown in tables 11 to 13 , employment for the poor is associated with a set of tradeoffs involving income, OOP health care expenditures, insurance status and access to care.

Table 11 shows the mean family income and mean OOP health care expenditures by employment status. As shown in the table, employment significantly raises the family income of the poor. For example, families that have 12 months of employment have a family income about 1.8 times greater than families with no employment $(\$ 11,467 \mathrm{vs}$. $\$ 6,491)$. However, OOP health care expenditures across the employment categories are not significantly different, except for families with more than 12 months of employment, who have significantly higher expenditures. The fact that employment raises the average income of the poor, while average OOP health care expenditures are nearly equivalent 
across working and non-working families, suggests that employment should reduce the financial burden of OOP health care expenditures.

Table 12 shows that employment is also associated with significant differences in health insurance coverage. For children, table 12 shows that there is a near perfect tradeoff of public coverage for private coverage as employment increases. For example, the BLS-like employment measure shows that working poor families, compared to nonworking poor families, have 14.4 percent more families having children with private coverage (25.0\% vs. $10.6 \%$ ) and 16.2 percent fewer families having children with public coverage (66.9\% vs. $83.1 \%$ ). However, it is not a perfect trade-off since there is some evidence that the uninsured rate among the children of the poor slightly increases with employment. For adults table 12 shows that employment significantly reduces health insurance coverage. For example, the BLS-like employment measure shows that working poor families, compared to non-working poor families, have 16.4 percent more families having an adult with private coverage (38.7\% vs. $22.3 \%$ ), 27.8 percent fewer families having an adult with public coverage ( $27.6 \%$ vs. $55.5 \%)$, and 11.4 percent more families with all adults uninsured (33.7\% vs. $22.3 \%$ ). The months of employment measure generally shows the same trend. For many poor adults, and some of their children, employer sponsored health insurance is not replacing the public coverage that is lost when entering the labor force, leaving many of the working poor uninsured.

Table 13 shows that employment is associated with reduced access to care for adults, but not for children. For example, looking at the BLS-like employment measure, the working poor, compared to the non-working poor, are much more likely to have an adult without a usual source of care (45.4\% vs. $30.3 \%)$, and much more likely to have an 
adult with no doctor visit during the year ( $43.4 \%$ vs. $24.8 \%)$. The months of employment measure shows the same trend. For children there are no significant differences across either employment measure regarding having a usual source of care or having a doctor visit during the year. For many poor adults entering the labor force is associated with losing a usual source of care and having fewer doctor visits.

\subsection{Multivariate Results}

The odds ratios for the logistic regression models are shown in table 14 and table 15. Only statistically significant values are shown. The iterative process described in section 3.6, step 1, although not shown, was used to arrive at these results. The goodness-of-fit measures and pseudo $\mathrm{R}^{2}$ are at the bottom of the tables. The dependent variables are high burden and very high burden, defined as a 10 percent and 20 percent financial burden from OOP health care expenditures, respectively. Table 14 shows the results using the BLS-like employment measure and table 15 shows the results using months of work with four categories. The goal of these models is to estimate the association of employment and the probability of having a high financial burden from OOP health care expenditures for poor families, while controlling for the other covariates of burden. The results for the two different employment measures will be presented in detail, while the other independent variables will presented more generally.

Controlling for a wide range of health, health care access, and demographic variables, these models show that employment is associated with reduced financial burdens from OOP health care expenditures. Table 14 shows that the working poor have an odds ratio of 0.55 for high burden and 0.44 for very high burden, compared to the nonworking poor. This indicates that employment for the poor reduced approximately by 
half the odds of having either a high or very high financial burden from OOP health care expenditures. Table 15 also shows that employment is associated with reduced burdens, except for families with a high burden and more than 12 months of work, which are not significantly different from families with zero months work. Compared to families with no work, families with 1 to 11 months of work had an odds ratio of 0.72 for high burden and 0.47 for very high burden; families with 12 months of work had an odds ratio of 0.55 for high burden and 0.37 for very high burden; families with more than 12 months of work were not different from families with no work for high burden, but had an odds ratio of 0.33 for very high burden. Taken together, the results in tables 14 and 15 show that employment generally reduces the financial burden of OOP health care expenditures for poor families.

Regarding the other demographic variables in the models, the age of the head-ofhousehold, having a child less than 18 years old, female headed household and region are not significant across all four models.

For the highest level of education of any family member, those with high school graduate or GED are not different from those with less than high school, but families with at least some college have much greater odds of having a high or very high burden, compared to families with less than high school. Families with a person 65 years old or older, compared to families without a person 65 or older, have an odds ratio of 2.51 or 2.58 , depending on the employment measure used, with respect to having a high burden, but are not significantly different with respect to having a very high burden.

The variables single parent family, married couple in the family, race, family size, MSA, and the interaction of race and single parent families, like most of the other 
demographic variables, were not identified in the literature as being covariates of burden, and were added as control variables without knowing what, if any, their significance might be. However, the results show that they have a significant impact on burden, but each affects only one of the burden measures. Single parent families are not different from all other families regarding their odds of having a high burden, but they are only half as likely to have a very high burden. Married couple families have an odds ratio of 1.67 or 1.53 for high burden, depending on the employment measure used, but they are not different from other families in their odds of having a very high burden. Regarding race, Hispanic families are not different from white families on either burden measure, but black families are less likely than white families to have a very high burden, but are equally likely to have a high burden. Families with only two persons have nearly twice the odds of single person families to have a very high burden but are equally likely to have a high burden, while families with three or more persons are not different than single person families on either burden measure. Families located in a MSA have an odds ration of 0.73 for high burden, as compared to families located outside a MSA, regardless of the employment measure used, but are equally likely to have a very high burden. The only interaction term, the interaction between race and single parent families, shows that Hispanic single parent families have an odds ratio of 1.68 for high burden, but are equally likely to have a very high burden, compared to white single parent families. Black single parent families are not different from white single parent families in terms of having a high or very high burden.

Uninsured families, and families with public health insurance, have lower odds of having either a high or very high burden than families with private health insurance. One 
exception is families with uninsured children and a very high burden, which are not different from families where the children have private insurance. Families where the children had no usual source of care, or no doctor visit, have equal odds of a high or very high burden compared to families that have a usual source of care or had doctor visits.

Families with an adult in fair or poor health have greater odds of having a high or very high burden, compared to families without an adult in fair or poor health. Families that have an adult with a chronic health condition have nearly twice the odds of having a high burden and over one and a half times the odds of having a very high burden. For children the results are mixed. Families with a child in fair or poor health are not different from other families with respect to having a high or very high burden. Families with a child that has a chronic health condition are not different from other families with respect to having a high burden, but have about one and a half times the odds of having a very high burden.

\subsection{Model Evaluation}

As outlined in section 3.6, step 3, three measures are used to evaluate the models. The three measures are the pseudo $\mathrm{R}^{2}$, the area under the ROC curve and the HosmerLemeshow chi-square test.

Regarding the explanatory power of these models, the pseudo $\mathrm{R}^{2}$ for all four models ranges from 0.21 to 0.23 . This indicates that each of the models is able to account for a significant portion of the variance in the dependent variable. The model for high burden using the BLS-like employment measure has the highest pseudo $\mathrm{R}^{2}$, but only marginally so. 
The area under the ROC curve is 0.81 for all four models, indicating they are all very good at discriminating between families with a positive outcome (having a high or very high burden) and a negative outcome (not having a high or very high burden). This value is calculated by pairing each family with a positive outcome with each family with a negative outcome. The area under the ROC curve is equivalent to the proportion of pairings where the family with a positive outcome had a probability of a positive outcome greater than that of the family with a negative outcome. Eighty-one percent of the time these models assign a higher probability to the family with a positive outcome.

All of the models fail the Hosmer-Lemeshow chi-square test. The HosmerLemeshow test is preferred when the number of covariate patterns is large relative to the number of cases, which is the case here (Hosmer and Lemeshow 2000). The HosmerLemeshow test breaks the probability of a positive outcome into deciles, commonly called the deciles of risk in health research, and calculates the chi-square statistic based on the number of observed cases minus the number of expected cases across these deciles. Failing the test indicates that the model does not accurately predict the probability of a high (or very high) burden for families across the entire range of the deciles of risk.

However, passing the Hosmer-Lemeshow chi-square test is not critical for the purpose to which these models are being put. The purpose of these models is to distinguish between those families with or without a high or very high burden, and they do that very well. In their text, Applied Logistic Regression, Hosmer and Lemeshow (2000) describe how a logistic regression model can be very good at discriminating between a positive and negative outcome, as measured by the area under the ROC curve, 
but poorly calibrated, as measured by the Hosmer-Lemeshow chi-square test. For example, suppose that a model has good fit and discriminates well, and then 0.25 is added to every probability. The model would then be poorly calibrated but the ability of the model to discriminate would not be affected. 


\section{CHAPTER 5}

\section{DISCUSSION}

The null hypothesis of this thesis, that employment for the poor is not associated with their level of health care expenditure burden, is rejected. The results presented here, both bivariate and multivariate, show that employment is associated with lowered health care expenditure burdens. In my literature search I found only one previously published study that examined the relationship between employment and the financial burden of OOP health care expenditures. That study, by Wyszewianski (1986), found that families with an employed head-of-household were less likely to have a high financial burden. That result is confirmed here. I find that employment for the poor reduced approximately by half the odds of having either a high or very high financial burden from OOP health care expenditures. However, the Wyszewianski (1986) study did not use a multivariate analysis that could control for the other covariates of burden. Therefore, the results of this thesis not only confirm the Wyszewianski (1986) finding but contribute to our understanding of this important subject by employing a multivariate analysis.

The central idea behind this thesis was that the increased uninsured rate among the working poor would increase the cost of their health care, possibly off-setting the increased income that employment provides them, or that the working poor would compensate for their reduced insurance coverage by consuming less health care. The bivariate results presented in table 11 showed that employment for the poor generally 
does not increase their OOP health care expenditures, but tables 12 and 13 showed that employment for the poor is associated with reduced health insurance coverage as well as reduced access to care, at least for adults. However, the multivariate results, controlling for health insurance and access to care, shows that employment for the poor does reduce their financial burden from OOP health care expenditures.

Using two different levels of burden, as well as two different employment measures, led to two interesting research questions that this thesis examines. The first question is, "Does employment for the poor have a differential impact on the probability of having a high burden ( $10 \%$ of family income) vs. a very high burden ( $20 \%$ of family income)?" Table 14 shows that employment for the working poor, compared to the nonworking poor, has odds ratios of 0.55 and 0.44 for high burden and very high burden, respectively. Table 15 shows the same pattern, with employment appearing to provide lower odds ratios for very high burden, relative to the odds ratios for high burden. Table 16 combines the results from tables 14 and 15 for the two different employment measures and shows the results of testing the difference between the odds ratios for the two burden measures. The results show that there is generally not a statistically significant difference in the odds ratios for high burden vs. very high burden. Employment for the poor does not have a differential impact on the probability of having a high burden vs. a very high burden. This suggests that future studies on this topic can confidently simplify their analysis by using only the 10 percent threshold for burden (high burden).

The second research question, "Is the estimated relationship between employment and OOP health care burden sensitive to the type of employment measure used?" is not entirely clear. Both measures show that employment generally reduces burden. 
However, the months of employment measure produced inconsistent results across the two burden measures, casting doubt upon the reliability of the measure. Taken together, these results suggest that there is no advantage in using an employment measure more complex than that used by the BLS in this analysis.

The results of this thesis have implications for social policy regarding the capacity of the labor market to provide adequate employment for the poor. Current social policy, as embodied in the Personal Responsibility and Work Opportunity Reconciliation Act (PRWORA) of 1996, explicitly states in its title that the poor simply need to reconcile their personal responsibility with their opportunities to find work. This policy ignores both the deficiencies in the labor market and the personal deficits that most poor persons have that limit their ability to succeed in the labor market. Further, this policy ignores the tradeoff of income, health insurance coverage and access to care associated with gaining employment and the impact of this tradeoff on the ability of the poor to afford and access adequate health care.

Although employment was shown to reduce the financial burden of OOP health care expenditures for the working poor relative to the non-working poor, the results presented here cast doubt on the capacity of the labor market to provide adequate employment for the poor. For example, nearly a third of working poor families spend 10 percent or more of their income on health care, and more than a third of working poor families have all adults who were uninsured all year. Too many working poor families face a high financial burden from OOP healthcare expenditures, and the reduced access to health care and risk associated with being uninsured. Compared to high income working families working poor families are three times as likely to have a high burden and ten 
times as likely to have an adult who is uninsured for the entire year (data not shown). The current social policy needs to be changed from one that "blames the victim," as the PRWORA implicitly does, to one that acknowledges the limitations of the labor market and the need to provide adequate education and training opportunities for the poor.

To address the limitations of the labor market I suggest that several changes need to be made. First, the minimum wage should be raised to $\$ 9.27 /$ hour, and adjusted for inflation annually. This is the 1968 minimum wage, the year that the minimum wage had the most buying power, adjusted for inflation to 2006 dollars. This would be $\$ 19,282$ per year for a full-time worker, nearly twice the poverty line for a single person, but below the poverty line for a family of four or more. Second, the Earned Income Tax Credit (EITC) should be used to keep all full-time working families' annual wages above 125 percent of the poverty line. Third, employer sponsored health insurance should be replaced with a publicly financed, single payer system where all persons are covered, regardless of employment status. Fourth, all employees should have at least two weeks of paid sick leave per year and last, child care subsidies should be given to workers with a family income below 250 percent of the poverty level. In the absence of a publicly financed health care system, this thesis suggests that welfare to work policies need to be concerned with health care related outcomes, including OOP health care expenditures burden, access to care and insurance coverage, which can insulate poor families from the risk of catastrophic health care expenditures. This could be accomplished by expanding Medicaid coverage and reimbursing poor families for health care expenditures that exceed 10 percent of their total family income. 
To address the personal deficits of the poor a fully funded welfare-to-work program should be created, including the payment of college and trade-school tuition, to raise the skills of the poor to better enable them to succeed in the labor market. These changes would greatly reduce poverty and provide every family in America protection from high OOP health care expenditures. 


\section{CHAPTER 6}

\section{SUMMARY AND CONCLUSIONS}

This thesis uses data from the 2002 Medical Expenditure Panel Survey to examine the relationship between employment and the financial burden of out-of-pocket health care expenditures for poor families. This was implemented by comparing the working poor to the non-working poor. This issue is more important now than in the past due to changes in the welfare system that have forced many welfare recipients into a labor market that generally pays the poor low wages and lacks benefits, such as health insurance and paid sick leave. The results show that employment for the poor reduces the financial burden of out-of-pocket health care expenditures by approximately half, relative to the non-working poor. This thesis contributes to the body of knowledge on this topic by employing a multivariate analysis, where the only other study on this topic, while finding a similar result, did not use multivariate analysis.

Although the results show that employment is associated with lower health care expenditure burden, the level of burden remains unacceptably high for the working poor, particularly when compared to working families with higher incomes. Further, this reduced burden comes at the cost of a reduction in overall health insurance coverage, a switch from free public coverage to private policies that require payment of premiums and a reduction in access to care. Although the multivariate model controls for these variables, the model does not capture the potential impact of changes in access to care 
and health insurance status on future health outcomes and exposure to risk from catastrophic health expenditures. Taken together, these results indicate that the current welfare policy is inadequate and changes to labor market, welfare and health policy are needed.

This thesis has several limitations, the use of retrospective data being perhaps the most serious. In most cases one respondent provides information for the entire family, covering a period of several months. While every effort is made to collect accurate data, there is undoubtedly some degree of error. Also, all of the independent variables cannot be known or measured. Although the models used in this thesis control for a wide variety of variables, there may be unobserved factors that influence both the decision to enter the labor market and the level of health care expenditures. Unfortunately, this type of study cannot be performed as a controlled experiment with families randomly assigned to a control or treatment group. Finally, a larger sample size would increase the statistical power of these models, particularly for subgroups of interest such as families where all the children were uninsured, families where at least one child had fair or poor health, and families with an adult 65 years old or older. 


\section{REFERENCES}

Acs, Gregory, Pamela Loprest and Tracy Roberts. 2001. "Final Synthesis Report of Findings from ASPE "Leavers" Grants." The Urban Institute.

Banthin, Jessica S. and Didem M. Bernard. 2006. "Changes in Financial Burdens for Health Care. National Estimates for the Population Younger Than 65 Years, 1996 to 2003." JAMA 296 (22).

Berk, Marc L. and Alan C. Monheit. 2001. "The Concentration of Health Care Expenditures, Revisited." Health Affairs March/April

Bureau of Labor Statistics. 2004. Report 976. September.

Galbraith, Alison, Sabrina Wong, Sue Kim and Paul Newacheck. 20115. "Out-of-Pocket Financial Burden for Low-Income Families with Children: Socioeconomic Disparities and Effects of Insurance." Health Services Research 40:6.

Guendelman, Sylvia and Michelle Pearl. 2001. "Access to Care for Children of the Working Poor." Archives of Pediatrics and Adolescent Medicire 155.

Gueron, J. and E. Pauly. 1991. From Welfare to Work. New York: Russell Sage Foundation.

Harrington, Michael. 1962. The Other America: Poverty in the United States. New York, NY: Simon \& Schuster.

Himmelstein, David, Elizabeth Warren, Deborah Thorne and Steffie Woolhandler. 2005. "Illness and Injury as Contributors to Bankruptcy." Health Affairs - Web Exclusive February.

Hosmer, David W. and Stanley Lemeshow. 2000. Applied Logistic Regression, second edition. Hoboken, NJ. John Wiley \& Sons, Inc.

Hwang, Wenke, Wendy Weller, Henry Ireys and Gerard Anderson. 2001. "Out-ofPocket Medical Spending for Care of Chronic Conditions." Health Affairs November/December 2001 
Hotz, Joseph, Charles Mullin and John Scholz. 2001. "The Earned Income Tax Credit and Labor Market Participation of Families on Welfare." Poverty Research News $5(3)$.

Kaplan, George, Kristine Siefert, Nalini Ranjit, Trivellore E. Raghunathan, Elizabeth A. Young, Diem Tran, Sandra Danziger, Susan Hudson, John W. Lynch and Richard Tolman. 2005. "The Health of Poor Women under Welfare Reform." American Journal of Public Health 95(7).

Karger, Howard J. 2003. "Ending Public Assistance: The Transformation of US Public Assistance Policy into Labor Policy." Journal of Social Policy 32(3):383-401.

Lindhorst, Taryn and Ronald Mancoske. 2006. "The Social and Economic Impact of Sanctions and Time Limits on Recipients of Temporary Assistance to Needy Families." Journal of Sociology and Social Welfare 33(1).

Loprest, Pamela and Sheila Zedlewski. 1999. "Current and Former Welfare Recipients: How Do They Differ?" The Urban Institute Discussion Paper 99-17.

Manning, Willard, Anirban Basu and John Mullahy. 2005. "Generalized Modeling Approaches to Risk Adjustment of Skewed Outcomes Data." Journal of Health Economics 24:465-488.

National Center for Health Statistics. 2004. "Health, United States, 2004 with Chartbook on Trends in the Health of Americans."

----. 2005. "Health, United States, 2005 with Chartbook on Trends in the Health of Americans."

O'Connor, Alice. 1998. "The False Dawn of Poor-Law Reform: Nixon, Carter, and the Quest for a Guaranteed Income." Journal of Policy History 10(1).

Patterson, James T. 2000. America's Struggle against Poverty in the Twentieth Century. Harvard University Press.

Seccombe, Karen. 1996. "Health Insurance Coverage Among the Working Poor: Changes from 1977 to 1987." Research in the Sociology of Health Care 13A:199227.

Selden, Thomas M and Didem M. Bernard. 2004. "Tax Incidence and Net Benefits in the Market for Employment-Related Insurance: Sensitivity of Estimates to the Incidence of Employer Costs." International Journal of Health Care Finance and Economics 4:167-192. 
Shen, Yu-Chu and Joshua McFeeters. 2006. "Out-of-Pocket Health Spending Between Low- and Higher-Income Populations: Who is at Risk of Having High Expenses and High Burdens?" Medical Care 44(3).

Short, Kathleen and Thesia L. Garner. 2002. "Experimental poverty measures: accounting for medical expenditures," Monthly Labor Review August.

VanGiezen, Robert and Albert Schwenk. 2001. "Compensation from before World War I through the Great Depression." Compensation and Working Conditions Fall.

World Health Organization. 2006. World Health Report, Core Health Indicators.

Wyszewianski, Leon. 1986. "Families with Catastrophic Health Care Expenditures." Health Services Research 21:5.

Zagorsky, Jay L. 1999. "Health and the Working Poor." Eastern Economic Journal $25(2)$. 
APPENDIX A -- FIGURES

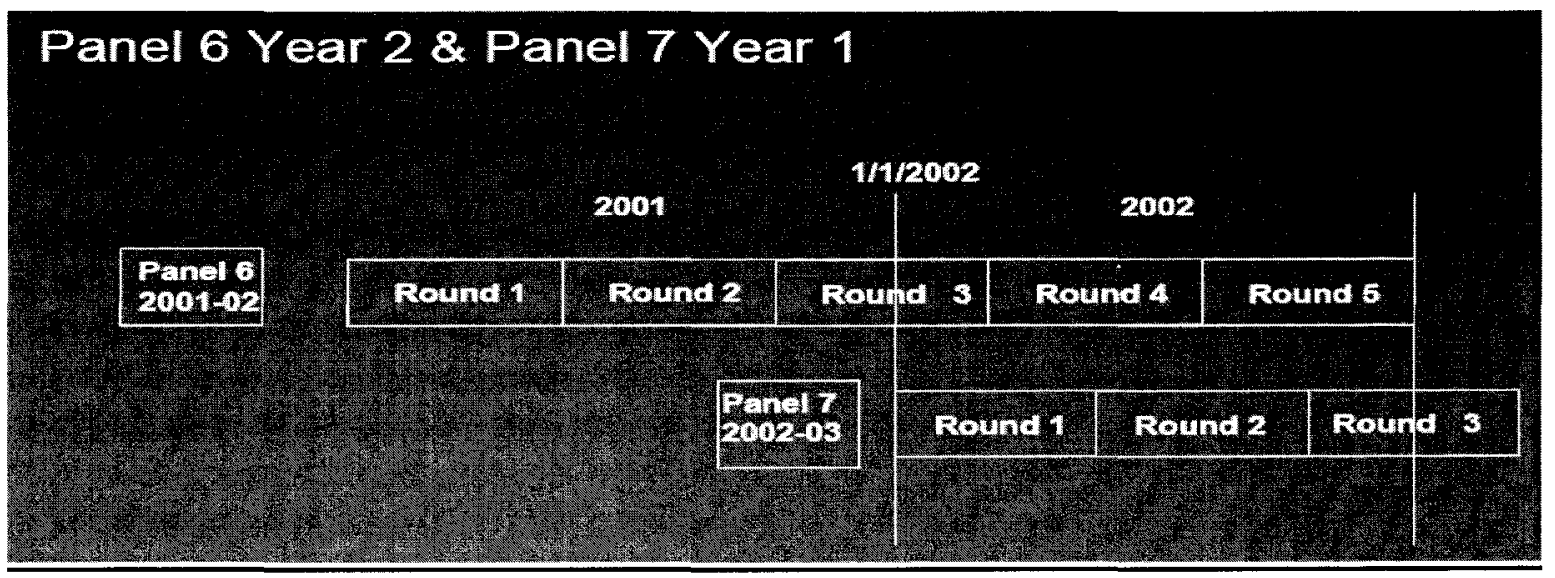

Figure 1: Overlapping panel design of the 2002 MEPS

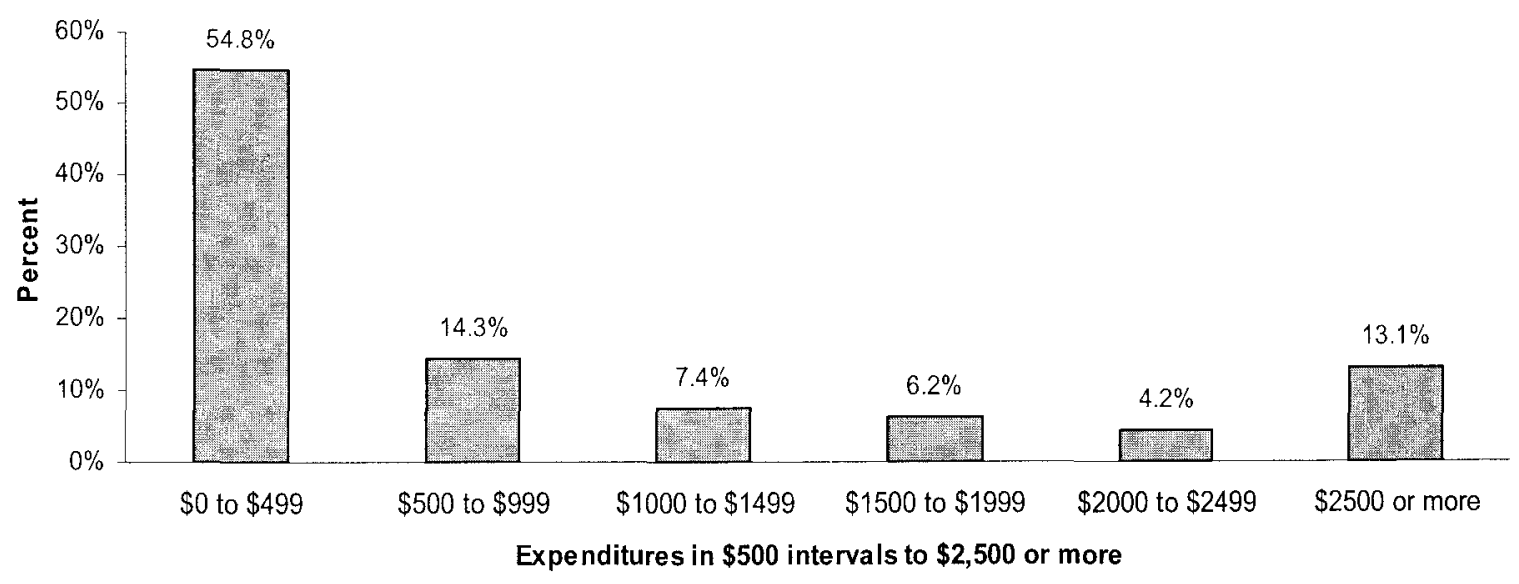

Figure 2: Family Out-Of-Pocket Health Care Expenditures for Poverty Families, 2002 MEPS 


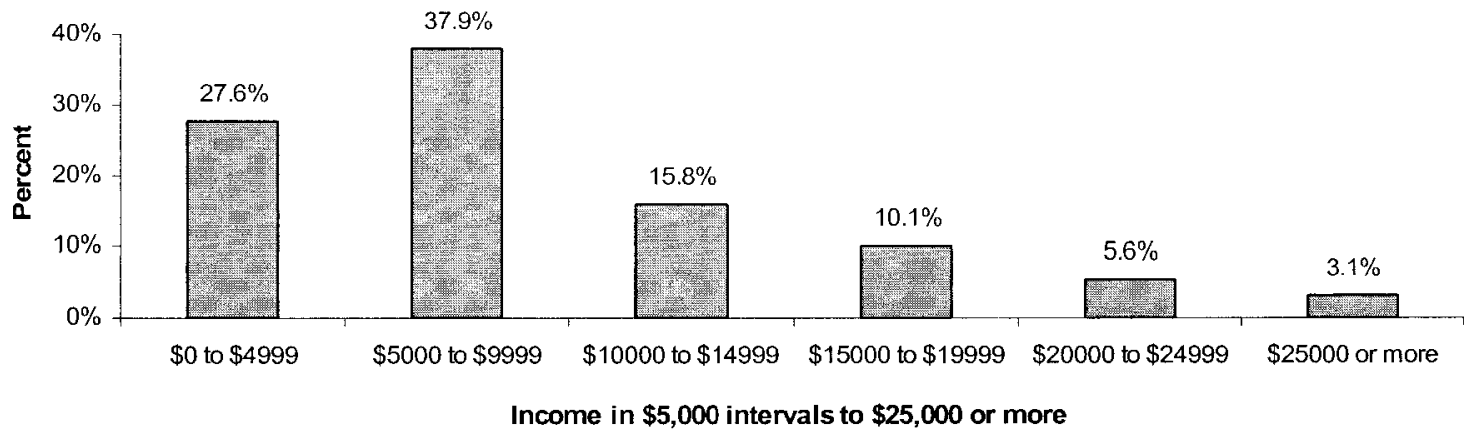

Figure 3: Family Income for Poverty Families, 2002 MEPS

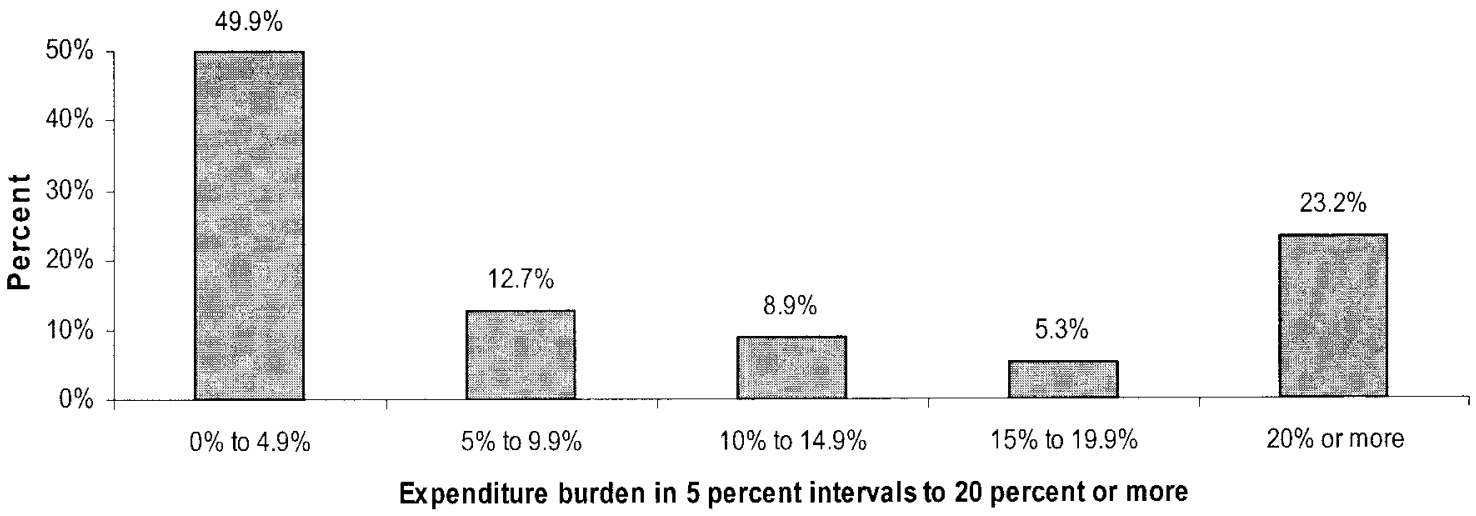

Figure 4: Health Care Expenditures as a Percent of Family Income for Poverty Families, 2002 MEPS 

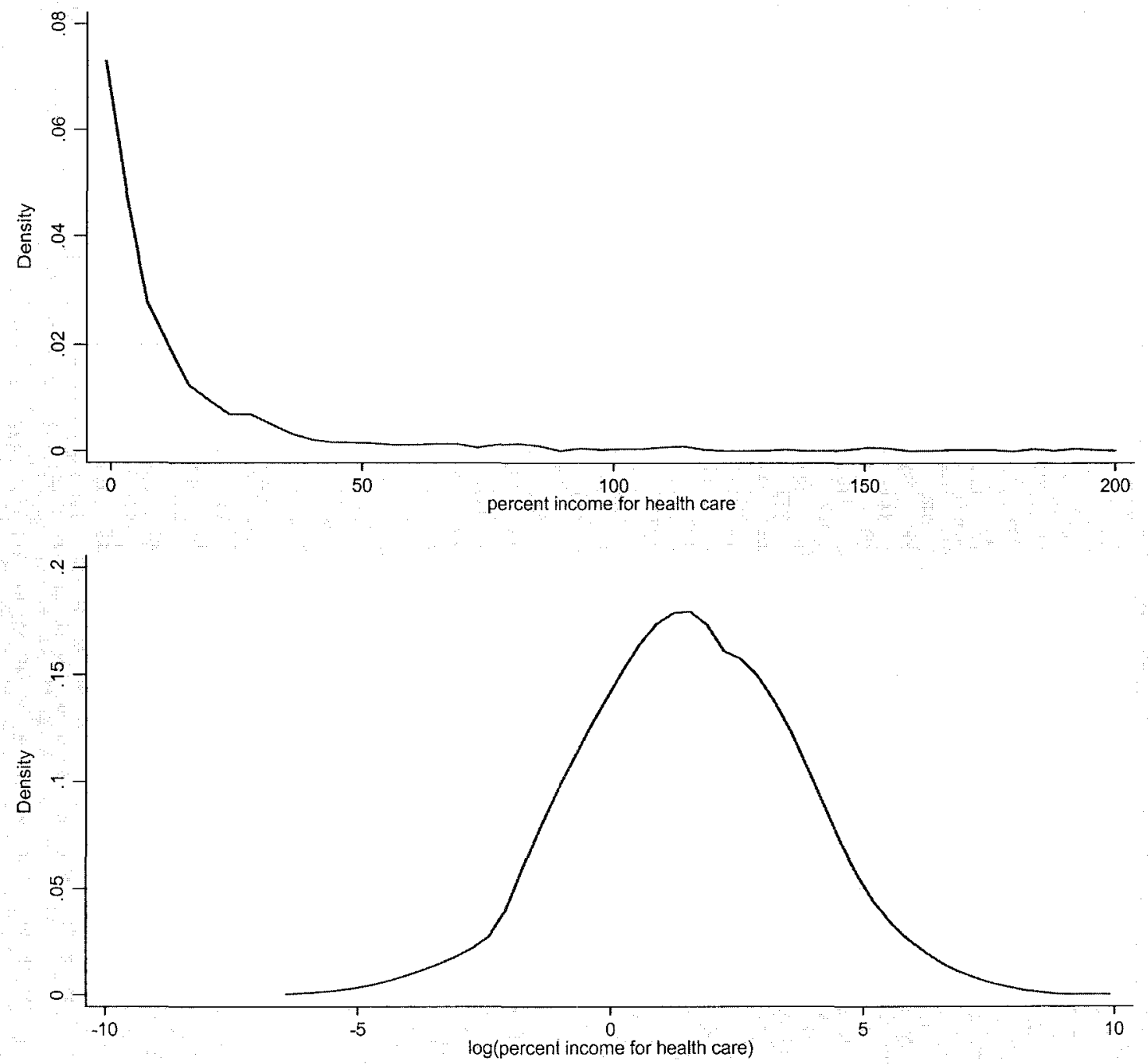

Figure 5: Probability density curves for the percent of family income used to pay OOP health care expenditures, before and after natural $\log$ transformation for poverty families, 2002 MEPS. The distribution of the percent income for health care is truncated at $200 \%$ for display purposes and actually extends to $7,336 \%$.

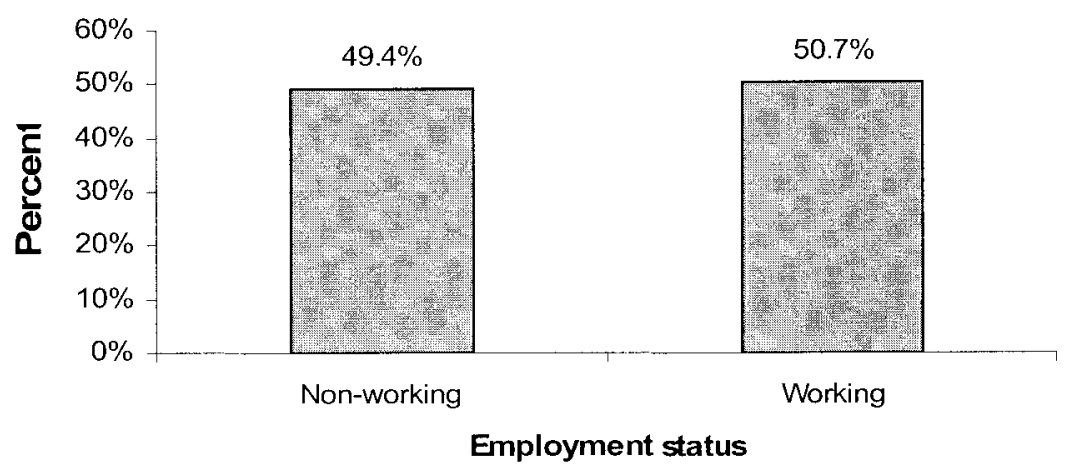

Figure 6: Employment status using a modified BLS definition for poverty families, 2002 MEPS 


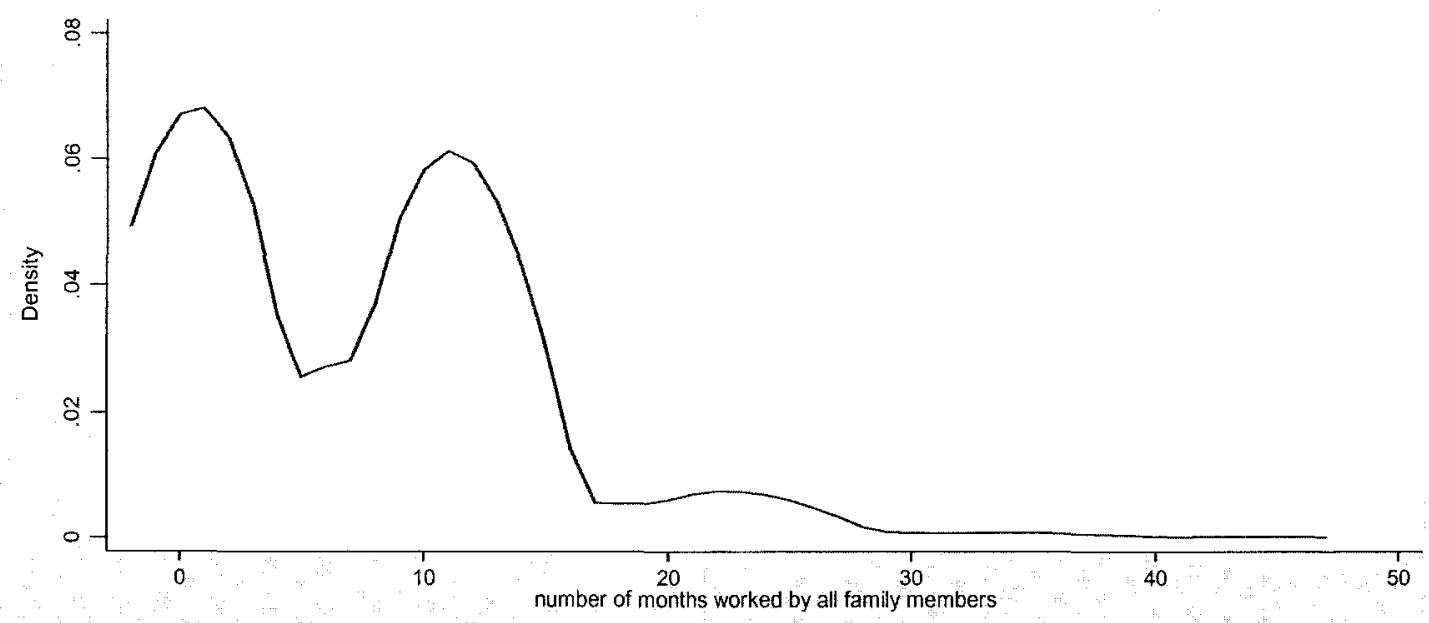

Figure 7: Probability density curve for the number of months worked for poverty families, 2002 MEPS. The theoretical distribution extends into negative numbers, but in reality no family has a negative number of months worked.

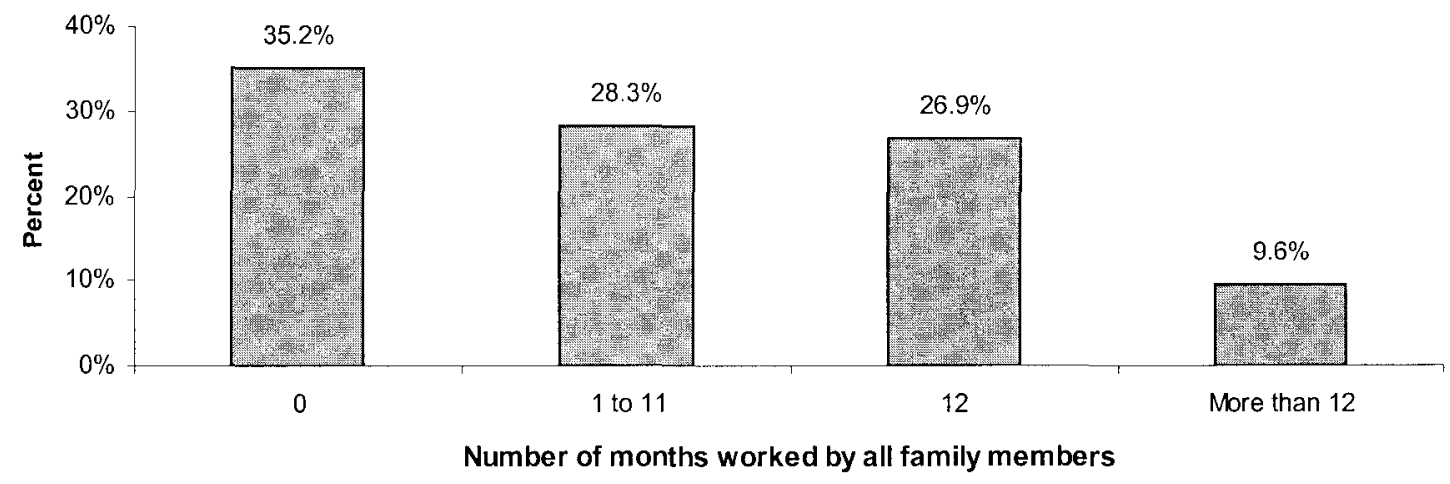

Figure 8. Categorized number of months worked for poverty families, 2002 MEPS 


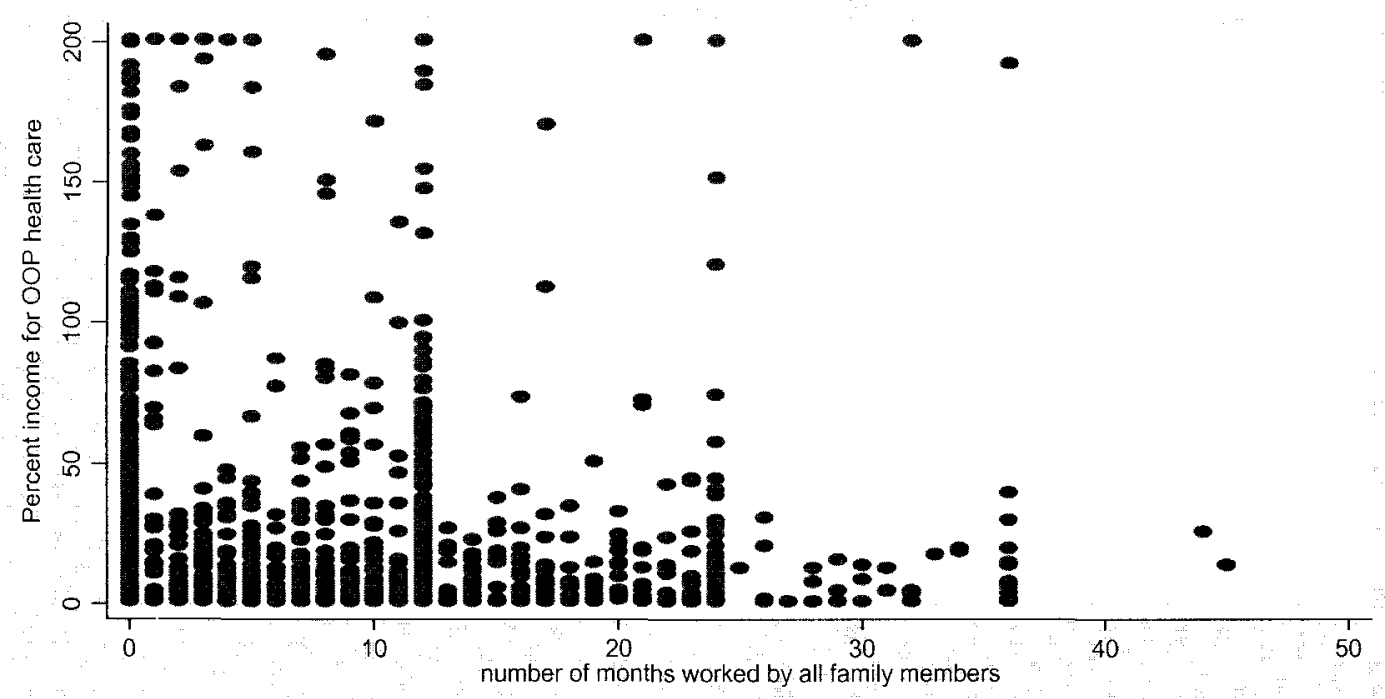

Figure 9. Scatter plot of months of work by percent of income spent on OOP health care, poverty families, 2002 MEPS. Percent of income spent on OOP health care is top coded at $200 \%$ for display purposes and actually extends to $7,336 \%$. Only $2.4 \%$ of all cases exceed $200 \%$.

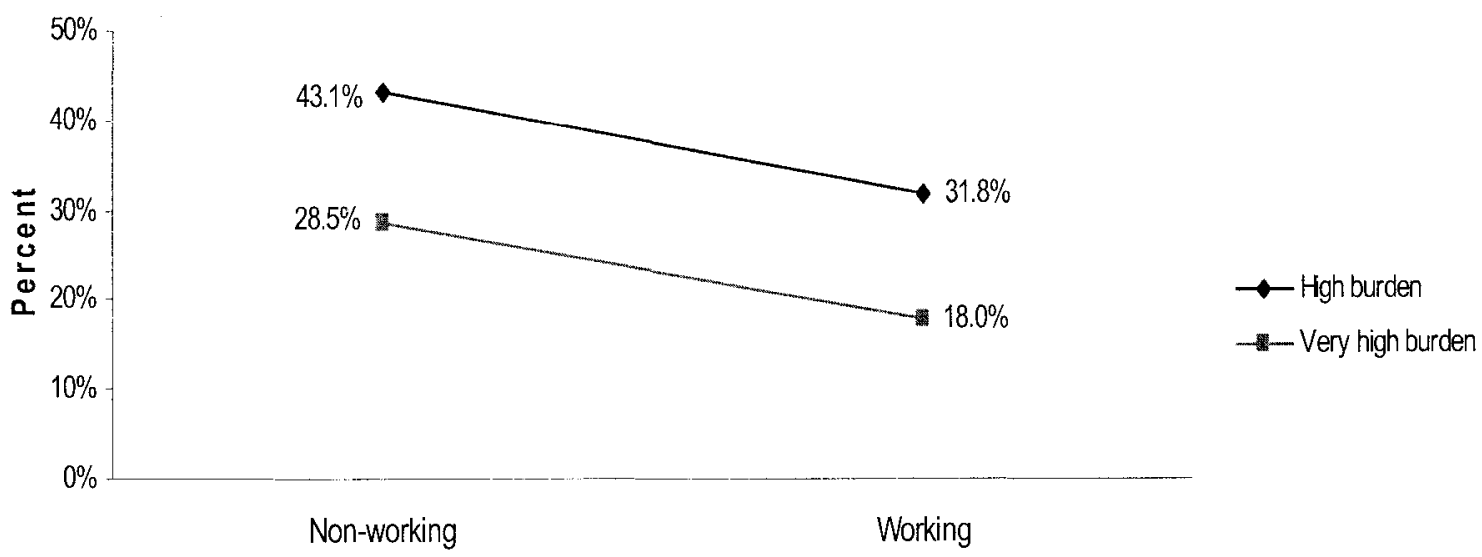

Employment status

Figure 10. Percent burden by employment status for poverty families, 2002 MEPS 


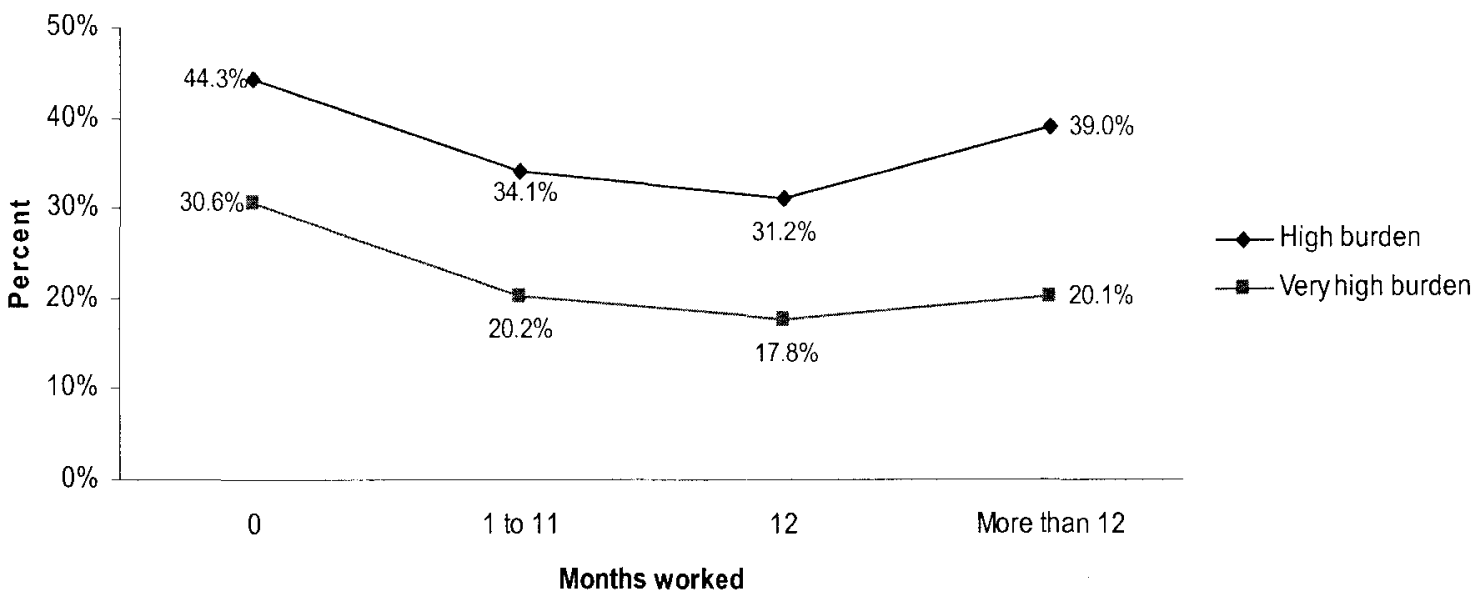

Figure 11. Percent burden by months worked for poverty families, 2002 MEPS 


\section{APPENDIX B - TABLES}

Table 1. Income status of all families, 2002 MEPS

\begin{tabular}{lccccc}
\hline & Total & $\begin{array}{c}\text { Poor/ } \\
\text { near poor }\end{array}$ & $\begin{array}{c}\text { Low } \\
\text { income }\end{array}$ & $\begin{array}{c}\text { Middle } \\
\text { income }\end{array}$ & $\begin{array}{c}\text { High } \\
\text { income }\end{array}$ \\
\hline Sample size & 12,729 & 2,770 & 1,930 & 3,908 & 4,121 \\
Weighted size (in millions) & 130.3 & 18.0 & 12.9 & 32.3 & 40.0 \\
Percent & 100.0 & 17.4 & 12.5 & 31.3 & 38.7 \\
SE percent & 0.00 & 0.57 & 0.39 & 0.56 & 0.75 \\
\hline
\end{tabular}

Table 2. Cross-tabulation of high burden and very high burden for poverty families, 2002 MEPS

\begin{tabular}{llrr}
\hline \multirow{2}{*}{ High burden } & \multicolumn{2}{c}{ Very high burden } \\
\cline { 2 - 4 } & & \multicolumn{1}{c}{ Yes } & \multicolumn{1}{c}{ No } \\
\hline \multirow{4}{*}{ Yes } & Sample size & 552 & 383 \\
& Percent & 23.21 & 14.16 \\
& SE percent & 1.08 & 0.93 \\
& Row percent & $\mathbf{6 2 . 1 0}$ & 37.90 \\
& SE row percent & 2.13 & 2.13 \\
& Column percent & 100.00 & 18.45 \\
& SE column percent & 0.00 & 1.16 \\
& Sample size & 0 & 1835 \\
& Percent & 0.00 & $\mathbf{6 2 . 6 3}$ \\
No & SE percent & 0.00 & 1.22 \\
& Row percent & 0.00 & 100.00 \\
& SE row percent & 0.00 & 0.00 \\
& Column percent & 0.00 & 81.55 \\
& SE column percent & 0.00 & 1.16 \\
\hline
\end{tabular}


Table 3. Demographic variables for poverty families, 2002 MEPS

\begin{tabular}{|c|c|c|}
\hline Variable & Percent & $\begin{array}{c}\text { Standard } \\
\text { error }\end{array}$ \\
\hline \multicolumn{3}{|l|}{ Age of the head-of-household } \\
\hline 18 to $24^{1}$ & 17.4 & 1.0 \\
\hline 25 to 44 & 48.7 & 1.3 \\
\hline 45 to 64 & 30.7 & 1.2 \\
\hline 65 or older & 3.2 & 0.4 \\
\hline \multicolumn{3}{|c|}{ Highest level of education of any family member } \\
\hline Less than high school ${ }^{1}$ & 28.6 & 1.1 \\
\hline High school graduate or GED & 57.2 & 1.3 \\
\hline At least some college & 14.2 & 1.0 \\
\hline \multicolumn{3}{|c|}{ At least one person 65 years old or older in the family } \\
\hline Yes & 4.8 & 0.5 \\
\hline No ${ }^{1}$ & 95.2 & 0.5 \\
\hline \multicolumn{3}{|c|}{ At least one child less than 18 years old in the family } \\
\hline Yes & 40.0 & 1.3 \\
\hline $\mathrm{No}^{1}$ & 60.0 & 1.3 \\
\hline \multicolumn{3}{|l|}{ Single parent family } \\
\hline Yes & 20.3 & 1.0 \\
\hline $\mathrm{No}^{1}$ & 79.7 & 1.0 \\
\hline \multicolumn{3}{|l|}{ Female headed household } \\
\hline Yes & 59.0 & 1.3 \\
\hline $\mathrm{No}^{1}$ & 41.0 & 1.3 \\
\hline \multicolumn{3}{|l|}{ Married couple in family } \\
\hline Yes & 22.4 & 1.0 \\
\hline $\mathrm{No}^{1}$ & 77.6 & 1.0 \\
\hline \multicolumn{3}{|l|}{ Race } \\
\hline Hispanic & 21.5 & 1.3 \\
\hline Black & 21.6 & 1.2 \\
\hline White or "other"1 & 56.9 & 1.6 \\
\hline \multicolumn{3}{|l|}{ Family size } \\
\hline $1^{1}$ & 48.3 & 1.4 \\
\hline 2 & 19.0 & 1.0 \\
\hline 3 or more & 32.6 & 1.1 \\
\hline \multicolumn{3}{|c|}{ Household is located in a metropolitan statistical area } \\
\hline Yes & 78.9 & 1.5 \\
\hline $\mathrm{No}^{1}$ & 21.1 & 1.5 \\
\hline \multicolumn{3}{|l|}{ Region } \\
\hline Northeast & 17.8 & 1.4 \\
\hline Midwest & 20.0 & 1.6 \\
\hline South & 39.1 & 1.6 \\
\hline West $^{1}$ & 23.2 & 1.5 \\
\hline
\end{tabular}

${ }^{T}$ Reference category 


\begin{tabular}{|c|c|c|}
\hline Variable & Percent & $\begin{array}{l}\text { Standard } \\
\text { error }\end{array}$ \\
\hline \multicolumn{3}{|l|}{ Health insurance status } \\
\hline At least one adult had private coverage at least part year ${ }^{1}$ & 30.6 & 1.1 \\
\hline $\begin{array}{l}\text { No adults had private coverage but at least one had public coverage at } \\
\text { least part year }\end{array}$ & 41.3 & 1.3 \\
\hline All adults were uninsured all year & 28.1 & 1.2 \\
\hline At least one child had private coverage at least part year ${ }^{1,2}$ & 20.3 & 1.3 \\
\hline $\begin{array}{l}\text { No children had private coverage but at least one had public coverage at } \\
\text { least part year }\end{array}$ & 72.2 & 1.4 \\
\hline All children were uninsured all year & 7.5 & 1.0 \\
\hline \multicolumn{3}{|l|}{ At least one adult had no usual source of care during the year } \\
\hline Yes & 38.0 & 1.3 \\
\hline $\mathrm{No}^{1}$ & 62.0 & 1.3 \\
\hline \multicolumn{3}{|l|}{ At least one adult had no doctor visit during the year } \\
\hline Yes & 34.2 & 1.1 \\
\hline $\mathrm{No}^{1}$ & 65.8 & 1.1 \\
\hline \multicolumn{3}{|l|}{ At least one child had no usual source of care during the year ${ }^{2}$} \\
\hline Yes & 16.6 & 1.3 \\
\hline No ${ }^{1}$ & 83.4 & 1.3 \\
\hline \multicolumn{3}{|l|}{ At least one child had no doctor visit during the year ${ }^{2}$} \\
\hline Yes & 35.3 & 1.6 \\
\hline $\mathrm{No}^{1}$ & 64.7 & $1 . .6$ \\
\hline
\end{tabular}

\footnotetext{
${ }^{\mathrm{l}}$ Reference category

${ }^{2}$ Percents calculated by sub-setting to families with children
} 
Table 5. Health status variables for poverty families, 2002 MEPS

\begin{tabular}{|c|c|c|}
\hline Variable & Percent & $\begin{array}{c}\text { Standard } \\
\text { error }\end{array}$ \\
\hline \multicolumn{3}{|c|}{ At least one adult has fair or poor physical health } \\
\hline Yes & 31.4 & 1.1 \\
\hline No ${ }^{1}$ & 68.6 & 1.1 \\
\hline \multicolumn{3}{|c|}{ At least one adult has a chronic health condition } \\
\hline Yes & 59.7 & 1.3 \\
\hline $\mathrm{No}^{1}$ & 40.3 & 1.3 \\
\hline \multicolumn{3}{|c|}{ At least one child has fair or poor physical health ${ }^{2}$} \\
\hline Yes & 8.5 & 0.8 \\
\hline $\mathrm{No}^{1}$ & 91.5 & 0.8 \\
\hline \multicolumn{3}{|c|}{ At least one child has a chronic health condition ${ }^{2}$} \\
\hline Yes & 36.7 & 1.5 \\
\hline $\mathrm{No}^{1}$ & 63.3 & 1.5 \\
\hline
\end{tabular}

${ }^{\mathrm{I}}$ Reference category

${ }^{2}$ Percents calculated by sub-setting to families with children

Table 6. Interaction terms for poverty families, 2002 MEPS

\begin{tabular}{lccccccc}
\hline & \multicolumn{2}{c}{ Overall } & & Within race & \multicolumn{2}{c}{$\begin{array}{c}\text { Subset to families } \\
\text { with children and } \\
\text { within race }\end{array}$} \\
\cline { 2 - 7 } Variable & Percent & $\begin{array}{c}\text { Standard } \\
\text { error }\end{array}$ & Percent & $\begin{array}{c}\text { Standard } \\
\text { error }\end{array}$ & $\begin{array}{c}\text { Percent } \\
\text { Standard } \\
\text { error }\end{array}$ \\
\hline Hispanic and single parent family & 5.0 & 0.4 & 23.1 & 1.4 & 39.6 & 2.2 \\
Black and single parent family & 6.5 & 0.7 & 30.0 & 3.0 & 65.1 & 3.9 \\
White/other and single parent family & 8.8 & 0.7 & 15.5 & 1.2 & 50.4 & 3.0 \\
\hline
\end{tabular}

${ }^{1}$ Reference category 


\section{Independent Variables}

Working (BLS-like definition)

Yes

Months of employment

0 month work ${ }^{1}$

1 to 11 months work

12 months work

More than 12 months work

Age of the head-of-household

$$
\begin{aligned}
& 18 \text { to } 24^{1} \\
& 25 \text { to } 44 \\
& 45 \text { to } 64 \\
& 65 \text { or older }
\end{aligned}
$$

Highest level of education of any family member

Less than high school ${ }^{1}$

High school graduate or GED

At least some college

At least one person 65 years old or older in the family

$$
\text { Yes }
$$

$\mathrm{No}^{1}$

At least one child less than 18 years old in the family

$$
\text { Yes }
$$

$\mathrm{No}^{1}$

Single parent family

$$
\begin{aligned}
& \text { Yes } \\
& \mathrm{No}^{1}
\end{aligned}
$$

Female headed household

Yes

10.82

14.37

$24.34^{* * *}$

40.69

$13.30^{* * *}$

25.73

\begin{tabular}{cccc} 
Yes & 10.63 & 37.74 & 24.37 \\
$\mathrm{No}^{1}$ & 7.39 & 36.85 & 21.54 \\
\hline
\end{tabular}

-- Table 7 is continued on the following page. 
Table 7. Distribution of burden across demographic variables for poverty families, 2002 MEPS -- continued

\section{Independent Variables}

Married couple in family

Yes

$\mathrm{No}^{1}$

Race

Hispanic

Black

White or "other"1

Family size

One $^{1}$

Two

Three or more

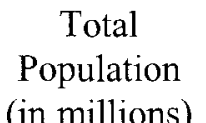

Dependent Variable

(in millions)

4.03

13.98

3.87

3.90

10.25

8.71

3.43

5.88

14.2

3.8

3.20

3.60

7.04

4.18
41.11

25.65

36.30

22.51

Household is located in a metropolitan statistical area

Yes

$\mathrm{No}^{1}$

Region

Northeast

Midwest

South

West $^{1}$

${ }^{1}$ Reference category for statistical test

${ }^{* * *} p<0.001$ (compared to the reference category)

** $p<0.01$

$\mathrm{p}<0.05$ 
Table 8. Distribution of burden across the access to care variables for poverty families, 2002 MEPS

\section{Independent Variables}

\begin{tabular}{|c|c|c|}
\hline \multirow{3}{*}{$\begin{array}{c}\text { Total } \\
\text { Population } \\
\text { (in millions) }\end{array}$} & \multicolumn{2}{|c|}{ Dependent Variable } \\
\hline & $\begin{array}{c}\text { High } \\
\text { Burden }\end{array}$ & $\begin{array}{c}\text { Very High } \\
\text { Burden }\end{array}$ \\
\hline & \multicolumn{2}{|c|}{ Percent } \\
\hline
\end{tabular}

Health insurance status

At least one adult had private coverage at least part year ${ }^{1}$ 5.51

61.83

43.18

No adults had private coverage but at least one had

public coverage at least part year

\subsection{5}

$27.16^{* * *}$

$14.18^{* * *}$

All adults were uninsured all year

\subsection{6}

$25.81^{* * *}$

$14.78^{* * *}$

At least one child had private coverage at least part year ${ }^{1,2}$

No children had private coverage but at least one had public coverage at least part year

$5.20 \quad 18.67^{* * *} \quad 8.42^{* * *}$

All children were uninsured all year

$0.54 \quad 19.66^{* * *}$

$10.47^{* * *}$

At least one adult had no usual source of care during the year

$$
\text { Yes }
$$

At least one adult had no doctor visit during the year

Yes

$\begin{array}{ccc}6.17 & 20.07^{* * *} & 10.89^{* * *} \\ 11.85 & 46.38 & 29.63\end{array}$

No ${ }^{1}$

$1.19 \quad 21.56^{*} \quad 12.18$

$\begin{array}{lll}16.82 & 28.31 & 14.85\end{array}$

$$
\text { No }{ }^{1}
$$

\footnotetext{
${ }^{1}$ Reference category for statistical test

${ }^{2}$ Percents calculated by first sub-setting to families with children.

${ }^{* * *} \mathrm{p}<0.001$

** $p<0.01$

* $p<0.05$
} 
Table 9. Distribution of the health status variables across burden for poverty families, 2002 MEPS

\section{Independent Variables}

At least one adult has fair or poor physical health

Yes

$\mathrm{No}^{1}$

At least one adult has a chronic health condition
Yes
$\mathrm{No}^{1}$

At least one child has fair or poor physical health ${ }^{2}$
Yes
$\mathrm{No}^{1}$

At least one child has a chronic health condition ${ }^{2}$

Yes

$\mathrm{No}^{1}$

${ }^{1}$ Reference category for statistical test

${ }^{2}$ Percents calculated by first sub-setting to families with children.

${ }^{* * *} \mathrm{p}<0.001$

** $p<0.01$

* $\mathrm{p}<0.05$

Table 10. Distribution of the interaction terms across burden for poverty families, 2002 MEPS

\begin{tabular}{lccc}
\hline & \multirow{2}{*}{$\begin{array}{c}\text { Total Population } \\
\text { (in millions) }\end{array}$} & \multicolumn{2}{c}{ Dependent Variable } \\
\cline { 3 - 4 } Independent Variables & & \multicolumn{2}{c}{ Percent } \\
\cline { 3 - 4 } Interaction terms & & 28.01 & 15.47 \\
$\quad$ Hispanic and single parent family & 0.90 & 18.82 & 8.52 \\
Black and single parent family & 1.17 & 26.34 & 15.60 \\
$\quad$ White/other and single parent family & 1.59 &
\end{tabular}

${ }^{1}$ Reference category for statistical test; none are significant 
Table 11. Distribution of income and expenditures across employment measures for poverty families, 2002 MEPS

\begin{tabular}{|c|c|c|c|c|c|c|}
\hline & \multicolumn{2}{|c|}{$\begin{array}{c}\text { BLS-like employment } \\
\text { measure }\end{array}$} & \multicolumn{4}{|c|}{ Months of employment } \\
\hline & $\begin{array}{c}\text { Not } \\
\text { Working }\end{array}$ & Working & $0^{1}$ & 1 to 11 & 12 & $>12$ \\
\hline & \multicolumn{6}{|c|}{ Mean } \\
\hline Total family income & $\$ 6,567$ & $\$ 12,177^{* * *}$ & $\$ 6,491$ & $\$ 8,300^{* * *}$ & $\$ 11,467^{* * *}$ & $\$ 17,606^{* * *}$ \\
\hline $\begin{array}{l}\text { Total family OOP health } \\
\text { care expenditures }\end{array}$ & $\$ 1,181$ & $\$ 1,151^{\mathrm{ns}}$ & $\$ 1,184$ & $\$ 1,047^{\mathrm{ns}}$ & $\$ 1,089^{\mathrm{ns}}$ & $\$ 1,664^{* * *}$ \\
\hline
\end{tabular}

Table 12. Distribution of employment measures across health insurance variables for poverty families, 2002 MEPS

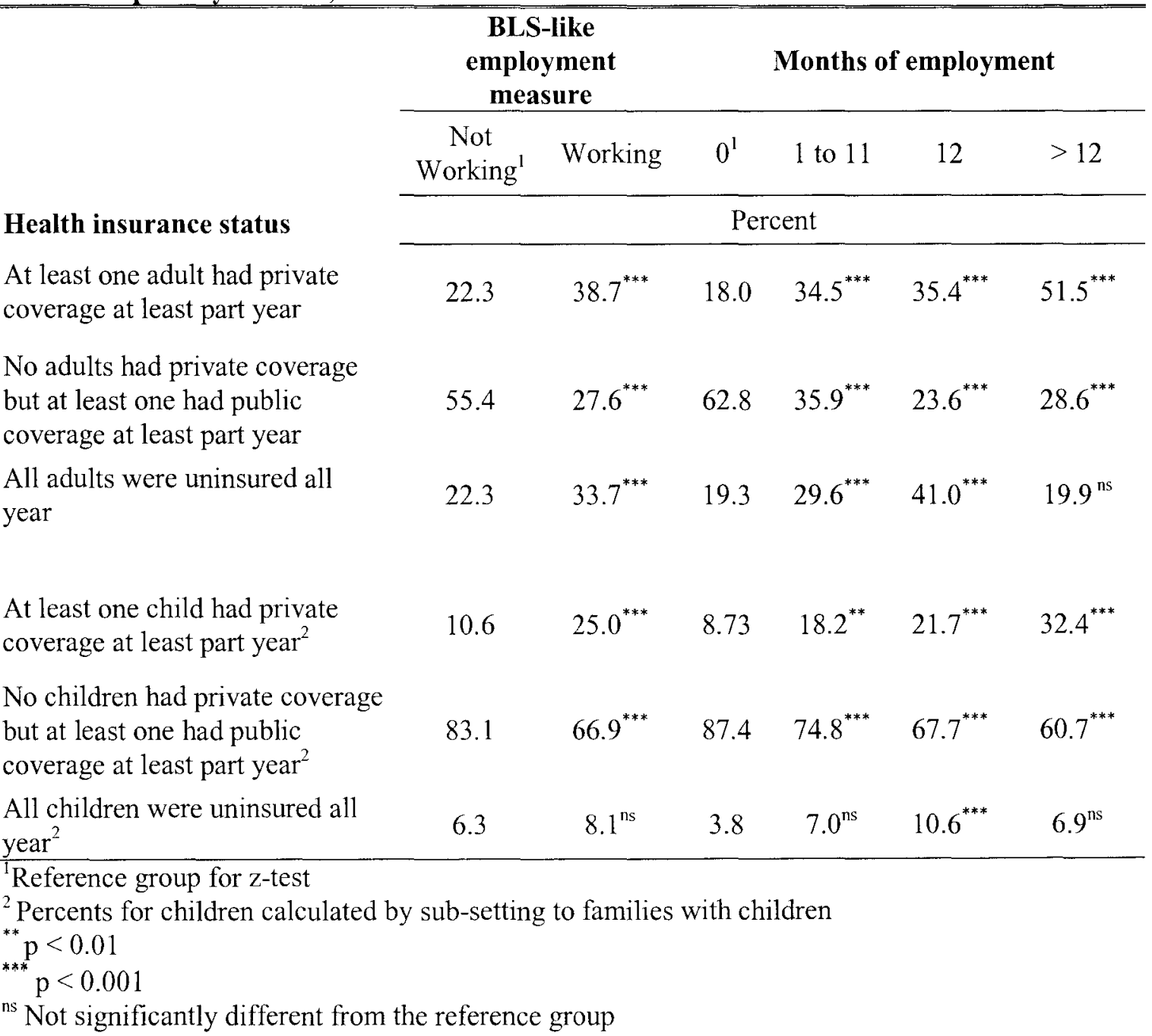


Table 13. Distribution of employment measures the across access to care variables for poverty families, 2002 MEPS

\begin{tabular}{|c|c|c|c|c|c|c|}
\hline \multirow{4}{*}{$\begin{array}{l}\text { Access to care } \\
\text { At least one adult had no usual } \\
\text { source of care during the year }\end{array}$} & \multicolumn{2}{|c|}{$\begin{array}{c}\text { BLS-like } \\
\text { employment } \\
\text { measure } \\
\end{array}$} & \multicolumn{4}{|c|}{ Months of employment } \\
\hline & $\begin{array}{l}\text { Not } \\
\text { Working }^{1}\end{array}$ & Working & $0^{1}$ & 1 to 11 & 12 & $>12$ \\
\hline & \multicolumn{6}{|c|}{ Percent } \\
\hline & 30.3 & $45.4^{* * *}$ & 25.1 & $44.2^{* * *}$ & $43.8^{* * *}$ & $50.1^{* * *}$ \\
\hline $\begin{array}{l}\text { At least one adult had no } \\
\text { doctor visit during the year }\end{array}$ & 24.8 & $43.4^{* * *}$ & 22.6 & $35.5^{* * *}$ & $40.2^{* * *}$ & $56.5^{* * *}$ \\
\hline $\begin{array}{l}\text { At least one child had no usual } \\
\text { source of care during the year }\end{array}$ & 15.7 & $17.0^{\mathrm{ns}}$ & 15.1 & $17.2^{\mathrm{ns}}$ & $14.8^{\mathrm{ns}}$ & $20.1^{\mathrm{ns}}$ \\
\hline $\begin{array}{l}\text { At least one child had no } \\
\text { doctor visit during the year }\end{array}$ & 32.2 & $36.7^{\mathrm{ns}}$ & 31.7 & $32.6^{\mathrm{ns}}$ & $38.1^{\text {ns }}$ & $37.9^{\text {ns }}$ \\
\hline
\end{tabular}


Table 14. Logistic regression results using BLS-like employment measure, poverty families, 2002 MEPS

\section{Independent Variables}

Working (BLS-like definition)

Working

Not working $^{1}$

\begin{tabular}{|c|c|}
\hline \multicolumn{2}{|c|}{ Dependent Variable } \\
\hline & \\
\hline Burden & $\mathrm{Bl}$ \\
\hline
\end{tabular}

Age of the head-of-household

18 to $24^{1}$

25 to 44

45 to 64

65 or older

Highest level of education of any family member

Less than high school ${ }^{1}$

High school graduate or GED

Odds Ratio

At least some college

At least one person 65 years old or older in the family

At least one child less than 18 years old in the family

Single parent family

Female headed household

Married couple in family

Race

Hispanic

Family size

One ${ }^{1}$

Two

Three or more

Household is located in a metropolitan statistical area

ns

Region

Northeast

ns

$$
\text { ns }
$$

Midwest

Health insurance status

At least one adult had private coverage at least part year ${ }^{1}$

No adults had private coverage but at least one had public coverage at least part year

$0.14 \quad 0.14$

All adults were uninsured all year

At least one child had private coverage at least part year ${ }^{1}$

No children had private coverage but at least one had 
Table 14. Logistic regression results using BLS-like employment measure, poverty families, 2002 MEPS -- Continued

\section{Independent Variables}

At least one adult has fair or poor physical health

At least one adult has a chronic health condition

At least one child had no usual source of care during the year

At least one child had no doctor visit during the year

At least one child has fair or poor physical health

At least one child has a chronic health condition

Dependent Variable

\begin{tabular}{cc}
$\begin{array}{c}\text { High } \\
\text { Burden }\end{array}$ & $\begin{array}{c}\text { Very High } \\
\text { Burden }\end{array}$ \\
\hline \multicolumn{2}{c}{ Odds Ratio } \\
\hline 1.55 & 1.54 \\
1.94 & 1.57 \\
$\mathrm{~ns}$ & $\mathrm{~ns}$ \\
$\mathrm{~ns}$ & $\mathrm{~ns}$ \\
$\mathrm{~ns}$ & $\mathrm{~ns}$ \\
$\mathrm{~ns}$ & 1.54
\end{tabular}

Interaction terms

Hispanic and single parent family

1.68 ns

Black and single parent family

White/other and single parent family ${ }^{1}$

ns ns

$1.00 \quad 1.00$

Pseudo $\mathrm{R}^{2}$

$0.23 \quad 0.21$

Goodness-of fit measures

Area under the ROC curve

0.81

0.81

Hosmer-Lemeshow chi-square $p$-value

0.00

0.00

${ }^{1}$ Reference category

ns - not statistically significant; variable was eliminated from the model 
Table 15. Logistic regression results using months of employment, poverty families, 2002 MEPS

\section{Independent Variables}

Months of employment

0 months work ${ }^{1}$

1 to 11 months work

12 months work

More than 12 months work

\begin{tabular}{|c|c|}
\hline \multicolumn{2}{|c|}{ Dependent Variable } \\
\hline Hig & \\
\hline Burden & \\
\hline
\end{tabular}

Age of the head-of-household

18 to $24^{1}$

45 to 64

Odds Ratio

65 or older

Highest level of education of any family member

Less than high school ${ }^{1}$

High school graduate or GED

At least some college

At least one person 65 years old or older in the family

At least one child less than 18 years old in the family

Single parent family

Female headed household

Married couple in family

Race

Hispanic

Black

White or "other"1

1.00

1.00

0.72

0.47

0.55

0.37

$0.71^{2}$

0.33

1.00

1.00

ns

ns

ns

ns

ns

ns

amily size

One $^{1}$

1.00

1.00

ns

ns

1.87

1.74

2.58

ns

ns

ns

ns $\quad 0.55$

ns ns

1.53

ns

Two

Three or more

Household is located in a metropolitan statistical area

ns

ns

ns

0.67

1.00

1.00

1.00

1.00

ns

ns

0.73

ns

ns

Region

Northeast

ns ns

Midwest

ns

ns

South

ns

ns

West $^{1}$

1.00

1.00

-- Table 15 is continued on the following page. 
Table 15. Logistic regression results using months of employment, poverty families, 2002 MEPS -- Continued

\section{Independent Variables}

Health insurance status

At least one adult had private coverage at least part year ${ }^{1}$

No adults had private coverage but at least one had public coverage at least part year

All adults were uninsured all year

At least one child had private coverage at least part year ${ }^{1}$

No children had private coverage but at least one had public coverage at least part year

All children were uninsured all year

At least one adult had no usual source of care during the year

At least one adult had no doctor visit during the year

At least one adult has fair or poor physical health

At least one adult has a chronic health condition

At least one child had no usual source of care during the year

At least one child had no doctor visit during the year

At least one child has fair or poor physical health

At least one child has a chronic health condition

Interaction terms

Hispanic and single parent family

Black and single parent family

White/other and single parent family ${ }^{1}$

Pseudo $\mathrm{R}^{2}$

Goodness-of fit measures

Area under the ROC curve

Hosmer-Lemeshow chi-square $p$-value

${ }^{1}$ Reference category

${ }^{2}$ Not statistically significant; this variable was left in the model so that the reference category remained families with zero months employment

ns - not statistically significant; variable was eliminated from the model

\begin{tabular}{cc}
\hline \multicolumn{2}{c}{ Dependent } \\
\hline High & Veriable High \\
Burden & Burden \\
\hline \multicolumn{2}{c}{ Odds Ratio } \\
\hline
\end{tabular}

1.00

1.00

0.15

0.13

0.32

0.28

1.00

1.00

0.39

0.44

0.45

ns

0.76

ns

$0.33 \quad 0.33$

$\begin{array}{ll}0.56 & 1.47\end{array}$

$1.93 \quad 1.56$

ns ns

ns ns

ns ns

ns $\quad 1.55$

1.68 ns

ns ns

$1.00 \quad 1.00$

0.22

0.21

$0.81 \quad 0.81$

$0.00 \quad 0.00$ 
Table 16. Comparing the association of employment and burden across the two burden measures for poverty families, 2002 MEPS

Employment Measures

BLS-like employment measure

Working

Not working

Months of employment

0 months work

1 to 11 months work

12 months work

More than 12 months work
Dependent Variable

\begin{tabular}{cc}
\hline High Burden & \multicolumn{2}{c}{ Very High Burden } \\
\hline \multicolumn{3}{c}{ Odds Ratio $^{2}$} \\
\hline 0.55 & $0.44^{\text {ns }}$ \\
1.00 & 1.00
\end{tabular}

1.00

1.00

0.72

$0.47^{\text {ns }}$

0.55

$0.37^{\text {ns }}$

$0.71^{3}$

$0.33^{*}$

\footnotetext{
${ }^{\mathrm{I}}$ Reference group for z-test

${ }^{2}$ The odds ratios presented here are taken from tables 14 and 15 .

${ }^{3}$ Not statistically significant; this variable was left in the model so that the reference category remained families with zero months employment

${ }^{\text {ns }}$ Not significantly different from the reference group ${ }^{*} \mathrm{p}<0.05$
} 


\section{CURRICULUM VITAE}

Name: William Alan Carroll

Address: 814 W. Burke Street

Martinsburg, WV 25401

DOB: Owensboro, Kentucky - August 19, 1960

Education

\& Training:

B.S. Sociology
University of Louisville
1987-1992

Employment: Bureau of the Census

Washington, DC

1995-2001

\author{
M.A. Sociology \\ University of Louisville \\ 1992-expected 2007
}

Agency for Healthcare Research and Quality Rockville, MD

2001-present

Government

Publications: Miller, G. Edward and William A. Carroll. 2005. "Trends in Children's Antibiotic Use: 1996 to 2001." Research Findings 23. AHRQ Pub. No. 05-0020.

Carroll, William A. 2005. "The Health Insurance Status of U.S. Workers, 2003: Estimates for Civilian Noninstitutionalized Workers Ages 16-64." Statistical Brief \#71. Web only publication: http://www.meps.ahrq.gov/mepsweb/data files/publications/st71/stat71.pdf

Carroll, William A. 2004. "Hypertension in America, 2002: Estimates for the U.S. Civilian Noninstitutionalized Population Ages 18 and Older." Statistical Brief \#59. Web only publication:

http://www.meps.ahrq.gov/mepsweb/data_files/publications/st59/stat59.pdf

Carroll, William A. and G. Edward Miller. 2004. "Trends in Antibiotic Use Among U.S. Children Aged 0 to 4 Years, 1996-2000." Statistical Brief \#35. Web only publication:

http://www.meps.ahrq.gov/mepsweb/data_files/publications/st35/stat35.pdf

Carroll, William A. 2003. "The Health Insurance Status of U.S.Workers, 2001: Estimates for U.S. Civilian Noninstitutionalized Workers Ages 1664." Statistical Brief \#11. Web only publication: http://www.meps.ahrq.gov/mepsweb/data files/publications/st11/stat11.pdf 